\title{
ARTICLE
}

Received 27 Oct 2014 | Accepted 27 May 2015 | Published 9 Jul 2015

DOI: $10.1038 /$ ncomms 8643

OPEN

\section{Telomeric G-quadruplexes are a substrate and site of localization for human telomerase}

\author{
Aaron L. Moye ${ }^{1, \star}$, Karina C. Porter ${ }^{1, \star}$, Scott B. Cohen ${ }^{1, \star}$, Tram Phan ${ }^{2}$, Katherine G. Zyner ${ }^{1}$, Natsuki Sasaki ${ }^{1}$, \\ George O. Lovrecz ${ }^{2}$, Jennifer L. Beck ${ }^{3} \&$ Tracy M. Bryan ${ }^{1}$
}

It has been hypothesized that G-quadruplexes can sequester the $3^{\prime}$ end of the telomere and prevent it from being extended by telomerase. Here we purify and characterize stable, conformationally homogenous human telomeric G-quadruplexes, and demonstrate that human telomerase is able to extend parallel, intermolecular conformations in vitro. These G-quadruplexes align correctly with the RNA template of telomerase, demonstrating that at least partial G-quadruplex resolution is required. A highly purified preparation of human telomerase retains this extension ability, establishing that the core telomerase enzyme complex is sufficient for partial G-quadruplex resolution and extension. The parallel-specific G-quadruplex ligand $\mathrm{N}$-methyl mesoporphyrin IX (NMM) causes an increase in telomeric G-quadruplexes, and we show that telomerase colocalizes with a subset of telomeric G-quadruplexes in vivo. The ability of telomerase to partially unwind, extend and localize to these structures implies that parallel telomeric G-quadruplexes may play an important biological role.

\footnotetext{
${ }^{1}$ Children's Medical Research Institute, University of Sydney, 214 Hawkesbury Road, Westmead, New South Wales 2145 , Australia. ${ }^{2}$ Commonwealth Scientific and Industrial Research Organisation, Manufacturing Flagship, 343 Royal Parade, Parkville, Victoria 3052, Australia. ${ }^{3}$ School of Chemistry, University of Wollongong, Northfields Avenue, Wollongong, New South Wales 2522, Australia. * These authors contributed equally to this work. Correspondence and requests for materials should be addressed to T.M.B. (email: tbryan@cmri.org.au).
} 
H uman chromosomes terminate with $\sim 5-10 \mathrm{~kb}$ of the telomeric DNA repeat TTAGGG ${ }^{1,2}$. The shortening of telomeres to a critical length is a signal for cellular senescence ${ }^{3,4}$. Telomere shortening is counteracted by telomerase, the telomere-specific reverse transcriptase that contains an RNA template to direct the addition of telomeric DNA by the catalytic telomerase reverse transcriptase (TERT) component ${ }^{5-7}$. Telomerase is upregulated in $\geq 85 \%$ of tumours, providing a telomere maintenance mechanism that contributes to cellular immortalization and tumour progression ${ }^{8,9}$.

Telomeric DNA can fold into compact G-quadruplex structures involving the interaction of four guanine bases in a square planar arrangement stabilized by central cations ${ }^{10}$. G-quadruplexes can form from one, two or four strands of DNA in a parallel or antiparallel orientation ${ }^{11}$. Over 375,000 sequences with the potential to form G-quadruplexes have been identified within the human genome ${ }^{12}$. There is increasing evidence supporting in vivo functions for DNA and RNA G-quadruplexes, including telomere protection and involvement in transcription, translation and splicing ${ }^{13-16}$. Direct evidence for the existence of G-quadruplexes at telomeres was obtained using specific antibodies against G-quadruplexes in the telomeric DNA of the ciliate Stylonychia lemnae ${ }^{17}$. Recently, a G-quadruplexspecific antibody has also been used to directly visualize G-quadruplexes throughout the human genome, a portion of which is located at telomeres ${ }^{18}$. There are a large number of small-molecule ligands that have specificity for G-quadruplexes, with many of them causing telomere dysfunction in vivo and inhibiting telomerase activity in vitro ${ }^{19-21}$.

The first report describing the inability of telomerase to extend G-quadruplexes, using the ciliate Oxytricha nova, did not differentiate between specific conformations as substrates ${ }^{22}$. In 2006, we demonstrated using purified G-quadruplex structures that some conformations can be extended by telomerase from the ciliated protozoa Tetrahymena thermophila and Euplotes aediculatus: parallel-stranded intermolecular G-quadruplexes were substrates for ciliate telomerase, whereas antiparallel intramolecular G-quadruplexes were not $^{23}$. Telomere biology is very different between ciliated protozoa and humans, and the telomerase ribonucleoproteins from the two groups differ in key properties such as the ability to extend non-telomeric DNA, the mechanism of template boundary definition and the components and multimeric state of the enzyme complex ${ }^{24-28}$. The possibility therefore existed that the ability to extend parallel G-quadruplexes is a ciliate-specific property of telomerase. Given the intense interest in telomerase inhibition by G-quadruplex stabilizers as a potential cancer therapeutic ${ }^{20,21}$, and the polymorphism of human telomeric G-quadruplexes ${ }^{11}$, we considered it important to determine the ability of human telomerase to extend defined conformations of G-quadruplex.

In this study, we establish that the ability to extend parallel intermolecular G-quadruplexes is conserved among evolutionarily distant species. We characterize purified, stable, conformationally homogenous human telomeric G-quadruplexes and demonstrate that human telomerase is able to recognize and partially unwind parallel intermolecular conformations and extend the unwound $3^{\prime}$ end in vitro. Treatment of immortal human cells with the parallel-specific G-quadruplex ligand $\mathrm{N}$-methyl mesoporphyrin IX results in a significant increase in G-quadruplexes present at telomeres in vivo, indicating the potential for formation of a parallel G-quadruplex structure at human telomeres. We show that human telomerase localizes to a subset of telomeres that contain G-quadruplexes in vivo.

\section{Results}

Folding and characterization of parallel G-quadruplexes. To test the ability of human telomerase to extend G-quadruplex DNA, we isolated and characterized parallel, intermolecular G-quadruplexes, since this is the conformation extended by ciliate telomerase ${ }^{23}$. To be certain that telomerase extends the G-quadruplex rather than its unfolded linear counterpart, it is necessary to work with structures with very slow unfolding rates under the conditions of a telomerase activity assay $\left(30^{\circ} \mathrm{C}, 1 \mathrm{~h}\right)$. Human telomeres have one less contiguous guanine residue than their ciliate counterparts (TTAGGG versus TTGGGG), which renders the corresponding G-quadruplexes less stable ${ }^{29}$. It is possible, however, to form stable human telomeric G-quadruplexes using cations such as $\mathrm{Sr}^{2+}$, rather than $\mathrm{K}^{+}$or $\mathrm{Na}^{+}$(refs 30,31). Tetramolecular G-quadruplexes formed from short oligonucleotides also tend to be relatively stable $e^{29,32}$.

The oligonucleotide 7GGT (Table 1) formed a tetrameric G-quadruplex, [7GGT] $]_{4}$, when annealed in buffer containing $150 \mathrm{mM} \mathrm{KCl}$, and gave a single band upon native gel electrophoresis. This band was purified from the native gel and remained $>98 \%$ pure after purification (Fig. 1a). The circular dichroism (CD) spectrum of $[7 \mathrm{GGT}]_{4}$ gave a positive signal at $260 \mathrm{~nm}$ and a negative signal at $240 \mathrm{~nm}$, characteristic of a parallel G-quadruplex (Fig. 1b) ${ }^{33}$. The ultraviolet thermal difference spectrum $(\mathrm{TDS})^{34}$ of $[7 \mathrm{GGT}]_{4}$ showed a negative peak at $295 \mathrm{~nm}$ (Supplementary Fig. 1a), supporting the assignment of a G-quadruplex structure 29,32 .

The oligonucleotide 22GGG (Table 1) gave rise to two bands on a native gel when annealed in $2.5 \mathrm{mM} \mathrm{Sr}^{2+}$ (Fig. 1c). The migration of the upper and lower bands was consistent with formation of intermolecular and intramolecular structures, respectively ${ }^{10}$. Each G-quadruplex band remained $\geq 95 \%$ pure after gel purification (Fig. 1c); no linear 22GGG was observed after purification. CD analysis of the upper band was indicative of a parallel G-quadruplex structure (Fig. 1d), whereas the lower band gave a maximum absorbance at $295 \mathrm{~nm}$ and a minimum at $260 \mathrm{~nm}$, consistent with an antiparallel structure (Fig. 1d). The TDS spectra for both the upper and lower bands of 22GGG confirmed G-quadruplex structures (Supplementary Fig. 1b,c).

Electrospray ionization mass spectrometry (ESI-MS) was used to determine G-quadruplex stoichiometry ${ }^{35,36}$. The purified 22GGG lower band gave predominant ions that were assigned to unimolecular species, consistent with the inclusion of an

Table 1 | Oligonucleotides used and G-quadruplex structures characterized in this study.

\begin{tabular}{|c|c|c|c|c|c|c|c|}
\hline Nomenclature & Sequence $\left(5^{\prime}-3^{\prime}\right)$ & $\begin{array}{l}\text { Length } \\
\text { (nt) }\end{array}$ & $\begin{array}{c}\text { G4 } \\
\text { nomenclature }\end{array}$ & $\begin{array}{l}\text { Annealing } \\
\text { cation }\end{array}$ & $\begin{array}{l}\text { Strand } \\
\text { orientation }\end{array}$ & $\begin{array}{l}\text { Strand } \\
\text { stoichiometry }\end{array}$ & $\begin{array}{l}T_{1 / 2} \\
\left({ }^{\circ} \mathbf{C}\right)\end{array}$ \\
\hline 7GGT & TTAGGGT & 7 & {$[7 \mathrm{GGT}]_{4}$} & $150 \mathrm{mM} \mathrm{K}^{+}$ & Parallel & Tetramer & 68 \\
\hline $22 G G G$ & AGGG(TTAGGG) 3 & 22 & {$[22 G G G]_{2}$} & $2.5 \mathrm{mM} \mathrm{Sr}^{2+}$ & Parallel & Dimer & $>90$ \\
\hline $9 \mathrm{C}$ & СССТААССС & 9 & & & & & \\
\hline $\mathrm{T}_{15}$ & TTTTTTTTTTTTTTт & 15 & & & & & \\
\hline $\mathrm{T}_{25}$ & TTTTTTTTTTTTTTTTTTTTTTTTT & 25 & & & & & \\
\hline
\end{tabular}



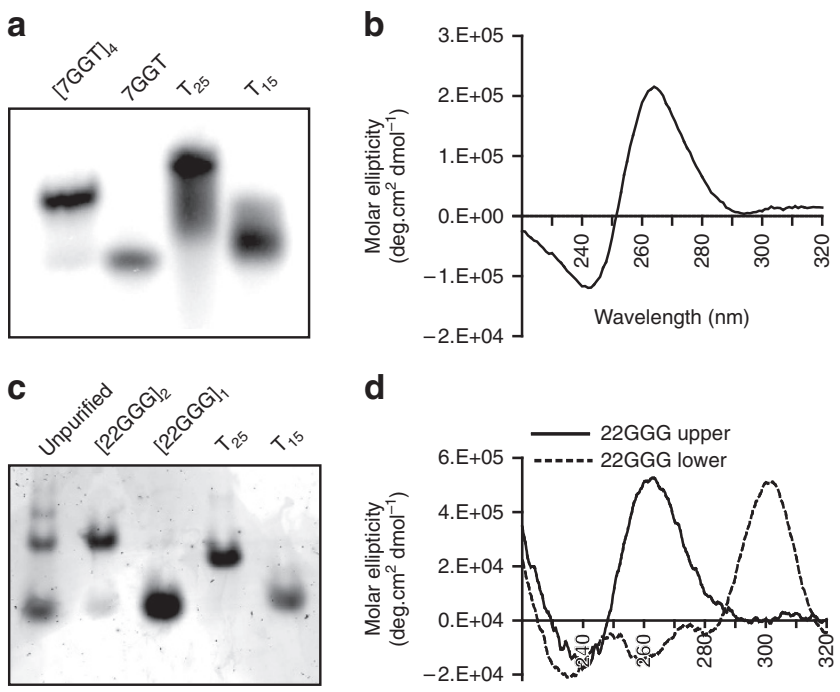

d
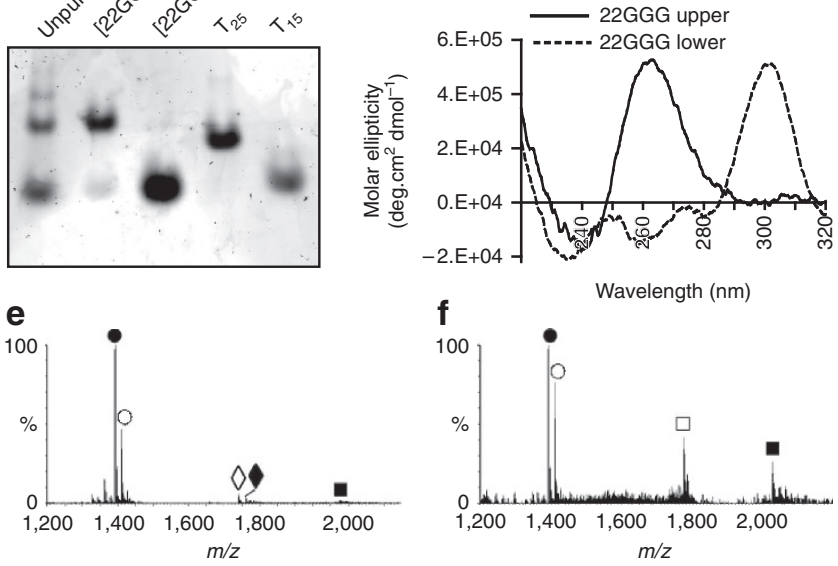

Figure 1 | Characterization of gel-purified telomeric G-quadruplexes.

(a) Native gel electrophoresis of purified ${ }^{32}$ P-labelled [7GGT] 4 in $150 \mathrm{mM}$ $\mathrm{K}^{+}$. Lane 1: $[7 \mathrm{GGT}]_{4}$ after gel purification. Lane 2: unfolded 7GGT. Lanes 3 and 4: $T_{25}$ and $T_{15}$ unstructured molecular weight (MW) markers.

(b) $\mathrm{CD}$ spectrum of gel-purified $[7 \mathrm{GGT}]_{4}$ in $150 \mathrm{mM} \mathrm{K}^{+}$. (c) Native gel electrophoresis of G-quadruplexes formed from 22GGG in $2.5 \mathrm{mM} \mathrm{Sr}^{2+}$, stained in SYBR Gold. Lane 1: unpurified folded 22GGG. Lane 2: postpurification folded $22 \mathrm{GGG}$ upper band, $[22 \mathrm{GGG}]_{2}$. Lane 3: post-purification 22GGG lower band, $[22 \mathrm{GGG}]_{1}$. Lanes 4 and 5: unstructured MW markers $T_{25}$ and $T_{15}$. (d) CD spectra of gel-purified 22GGG G-quadruplexes in $2.5 \mathrm{mM} \mathrm{Sr}^{2+}$. (e) Negative ion ESI mass spectra of the lower band of folded 22GGG and (f) the upper band of folded 22GGG. $[\mathrm{M}-5 \mathrm{H}]^{5-}$; $\diamond[\mathrm{M}-4 \mathrm{H}]^{4-} ; \mathrm{O}\left[\mathrm{M}+\mathrm{Sr}^{2+}-7 \mathrm{H}\right]^{5-} ; \bullet\left[\mathrm{M}+\mathrm{Sr}^{2+}-6 \mathrm{H}\right]^{4-}$;

a $\left[2 \mathrm{M}+3 \mathrm{Sr}^{2+}-13 \mathrm{H}\right]^{7-} ; \square\left[2 \mathrm{M}+3 \mathrm{Sr}^{2+}-14 \mathrm{H}\right]^{8-}$.

$\mathrm{Sr}^{2+}$ ion within an intramolecular G-quadruplex (Fig. 1e; Supplementary Table 1). A lower-abundance ion can be assigned as the dimeric G-quadruplex species $\left[2 \mathrm{M}+3 \mathrm{Sr}^{2+}\right.$. $13 \mathrm{H}]^{7-}$ (where $\mathrm{M}$ is neutral, unimolecular 22GGG), consistent with the observation of some reformation of the upper parallel G-quadruplex after purification. Together, the migration pattern on native gel electrophoresis, ESI-MS and CD analysis indicate that the lower band of 22GGG annealed in $\mathrm{Sr}^{2+}$ is an intramolecular antiparallel G-quadruplex, which will henceforth be referred to as $[22 \mathrm{GGG}]_{1}$.

The predominant ions observed from the purified upper band of 22GGG represented bimolecular DNA along with a unimolecular G-quadruplex (Fig. 1f; Supplementary Table 1); this is consistent with the observation of some upper band converting to the intramolecular G-quadruplex after purification. The ESI mass spectrum, combined with CD and TDS analysis and native gel electrophoresis, is consistent with a parallel, dimeric G-quadruplex, here called $[22 \mathrm{GGG}]_{2}$.

Absence of spontaneous unfolding of G-quadruplexes. The relative stabilities of the purified G-quadruplexes were initially assessed by determining their melting temperatures. Since intermolecular G-quadruplexes reform very slowly and are therefore not at equilibrium during the measurement, we refer to this value as $T_{1 / 2}$ rather than $T_{\mathrm{m}}$, which is the true thermodynamic parameter at equilibrium ${ }^{29}$. The ultraviolet melting curve of [7GGT] $]_{4}$ gave a $T_{1 / 2}$ of $68^{\circ} \mathrm{C}$ (measured at a heating rate of $1{ }^{\circ} \mathrm{C} \mathrm{min}^{-1}$; Supplementary Fig. 1d; Table 1).

To determine the amount of [7GGT $]_{4}$ that unfolds during the course of a telomerase activity assay $\left(30^{\circ} \mathrm{C}, 1 \mathrm{~h}\right)$, we employed a complementary C-strand trap assay. A 10-fold excess of C-rich complementary strand (Table 1) was added to the G-quadruplex in the same buffer used for telomerase activity assays (described below), and the extent of Watson-Crick duplex formation was monitored over $4 \mathrm{~h}$ by non-denaturing gel electrophoresis ${ }^{37,38}$ (Fig. 2a). Control experiments established that the result was unaffected by increasing C-strand concentrations, up to 100 -fold over G-quadruplex (Supplementary Fig. 2a), demonstrating that the rate of Watson-Crick duplex formation reflects the rate of G-quadruplex unfolding. After $1 \mathrm{~h}$ at $30^{\circ} \mathrm{C}, \sim 1 \%$ of the G-quadruplex had hybridized to the complementary strand, with $\sim 3-4 \%$ hybridized after $4 \mathrm{~h}$ (Fig. 2a,b). As a further test of the stability of $[7 \mathrm{GGT}]_{4}$, the G-quadruplex was treated with phosphodiesterase 1 (P1), which cleaves single-stranded DNA exonucleolytically at the $3^{\prime}$ end. Under conditions identical to the telomerase activity assays below $\left(30^{\circ} \mathrm{C}\right.$ for $1 \mathrm{~h}$ ), all of the $\mathrm{P} 1$-treated linear $7 \mathrm{GGT}$ was digested while no $[7 \mathrm{GGT}]_{4}$ digestion was detected (Fig. 2c). The 7-nt oligonucleotide remained intact after digestion, demonstrating that even the single thymidine at the $3^{\prime}$ end of each of the four strands is participating in tertiary structure and being protected from digestion. Overall, these data demonstrate that the G-quadruplex $[7 \mathrm{GGT}]_{4}$ is stable under the conditions of the telomerase activity assay.

The $T_{1 / 2}$ values of $[22 \mathrm{GGG}]_{2}$ and $[2 \mathrm{GGG}]_{1}$ were $>90$ and $68^{\circ} \mathrm{C}$, respectively, when measured at $1^{\circ} \mathrm{C} \mathrm{min}-1$ (Supplementary Fig. 1e,f; Table 1). The high melting temperature of the dimeric species indicates that it is an exceptionally stable structure. An identical complementary C-strand experiment was performed with $[22 \mathrm{GGG}]_{2}$ in $2.5 \mathrm{mM} \mathrm{Sr}^{2}+$ buffer. After $4 \mathrm{~h}$ at $30{ }^{\circ} \mathrm{C}$, there was no observable duplex formation, indicating that the $[22 \mathrm{GGG}]_{2}$ G-quadruplex does not unfold under our assay conditions (Fig. 2d). This was confirmed by digestion with P1 at $30^{\circ} \mathrm{C}$ for $1 \mathrm{~h}$; no digestion of [22GGG] $]_{2}$ was observed (Fig. 2e,f, right lanes). It should be noted that any [22GGG $]_{2}$ that did unfold over days or weeks in storage rapidly formed $[22 \mathrm{GGG}]_{1}$, with no linear 22GGG oligonucleotide observed (Fig. 1c).

Intramolecular G-quadruplexes often display rapid folding and unfolding rates ${ }^{23,39}$. Under the conditions used in this study, it was not possible to obtain a native gel or $\mathrm{CD}$ spectrum that corresponded to linear, unfolded 22GGG in the presence of $2.5 \mathrm{mM} \mathrm{SrCl} 2$. When incubated with $\mathrm{P} 1$, only $\sim 30 \%$ of 'linear' 22GGG in $2.5 \mathrm{mM} \mathrm{SrCl}_{2}$ was digested (Fig. 2e,f, middle lanes). This suggests that linear $22 \mathrm{GGG}$ in the presence of $\mathrm{Sr}^{2+}$ is in rapid equilibrium with [22GGG $]_{1}$. To confirm this, we 'locked' linear 22GGG into an unfolded conformation by pre-binding it with the 9C complementary oligonucleotide (Supplementary Fig. 2b), as previously described ${ }^{39}$. After digestion with P1, only $10 \%$ of the DNA remained undigested (Fig. 2e,f, left lanes). These data demonstrate that the P1 exonuclease was functional in this experiment, and that linear 22GGG and intramolecular [22GGG $]_{1}$ G-quadruplex are in rapid equilibrium when in the presence of $2.5 \mathrm{mM} \mathrm{Sr}^{2+}$.

Parallel G-quadruplexes are substrates of human telomerase. Telomerase activity assays were performed with the G-quadruplexes characterized above to determine whether parallel, intermolecular G-quadruplexes are a substrate for human telomerase. Telomerase was prepared by overexpressing its 
a
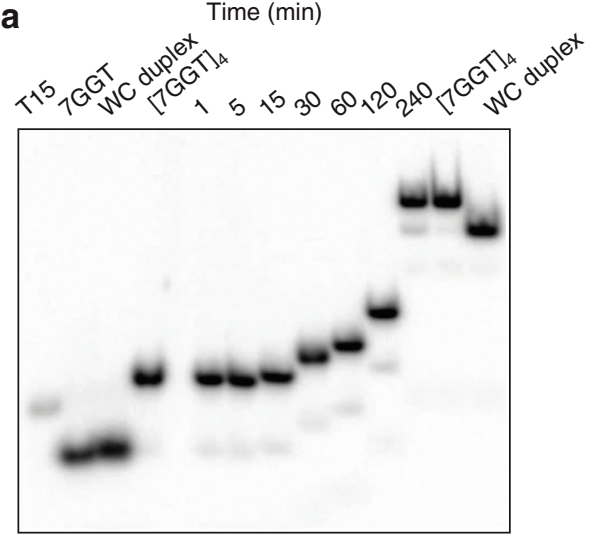

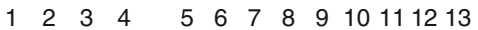

d

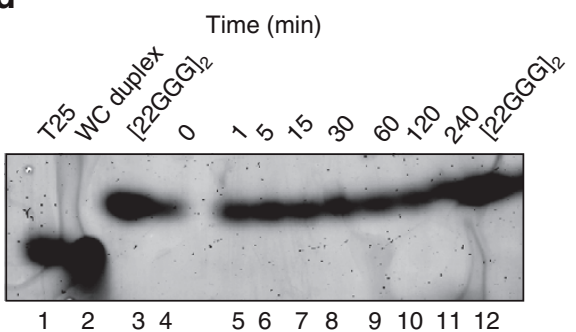

b
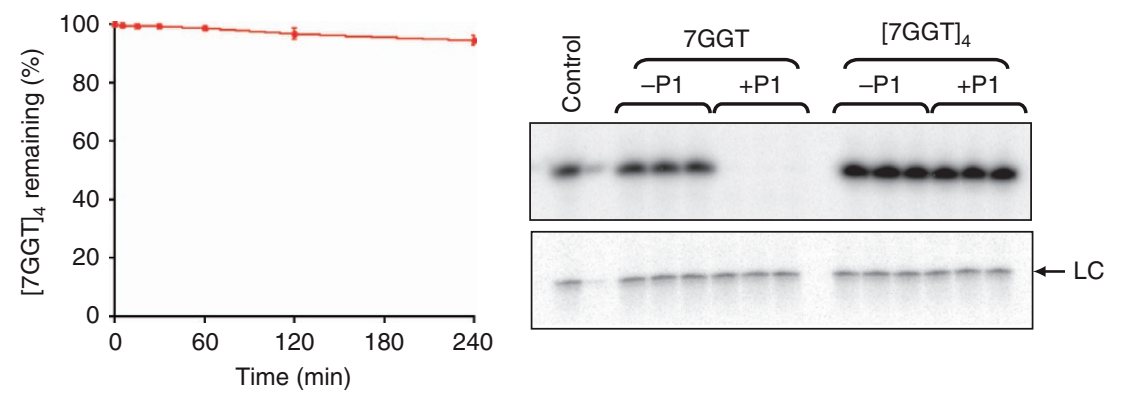

e

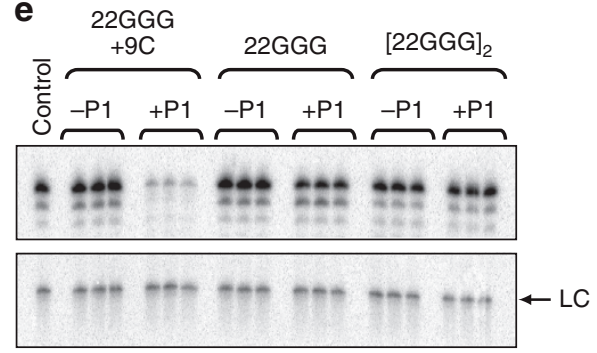

C

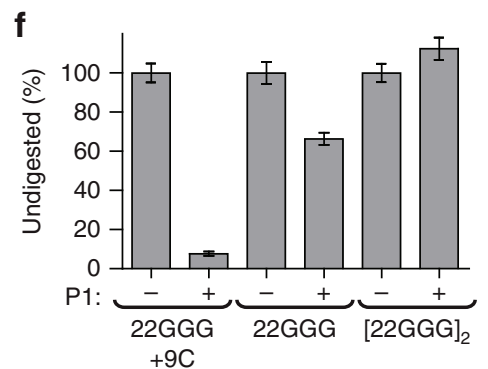

Figure 2 | Stability of telomeric G-quadruplexes. (a) $[7 \mathrm{GGT}]_{4}$ complementary strand trap assay: $5^{\prime}$-end-labelled [7GGT] $]_{4}$ in $150 \mathrm{mM} \mathrm{K}+$, incubated with 10 -fold excess complementary strand $9 \mathrm{C}$ at $30^{\circ} \mathrm{C}$ and electrophoresed on a $12 \%$ non-denaturing polyacrylamide gel. Lane 1: unstructured molecular weight (MW) marker $\mathrm{T}_{15}$. Lane 2: denatured 7GGT. Lane 3: pre-annealed Watson-Crick (WC) duplex. Lane 4: gel-purified [7GGT] 4 G-quadruplex. Lanes 5-11: $[7 \mathrm{GGT}]_{4}$ incubated with $9 \mathrm{C}$ at $30^{\circ} \mathrm{C}$ for the indicated times. Lane 12: [7GGT] 4 . Lane 13: pre-annealed WC duplex. Samples were loaded at the times indicated, with the gel running between loadings, so later samples underwent shorter electrophoresis times. The last three lanes were loaded simultaneously. (b) Proportion of $[7 \mathrm{GGT}]_{4}$ remaining over time at $30^{\circ} \mathrm{C}$. Error bars represent s.d. of the mean of three independent experiments. (c) P1 digestion of 7GGT and [7GGT] 4 electrophoresed on a 12\% denaturing polyacrylamide gel; digestions were performed in triplicate. Control lane: end-labelled 7GGT. (d) $[22 \mathrm{GGG}]_{2}$ complementary strand trap assay. Unlabelled [22GGG $]_{2}$ in $2.5 \mathrm{mM} \mathrm{Sr}{ }^{2+}$, incubated with 10 -fold excess complementary strand $9 \mathrm{C}$ at $30^{\circ} \mathrm{C}$, electrophoresed on a $16 \%$ non-denaturing polyacrylamide gel and stained in SYBR Gold. Lane 1: unstructured MW marker $\mathrm{T}_{25}$. Lane 2: pre-annealed WC duplex. Lane 3: gel-purified [22GGG]2. Lanes 4-11: G-quadruplex [22GGG] ${ }_{2}$ incubated with $9 \mathrm{C}$ at $30^{\circ} \mathrm{C}$ for the indicated times. Lane 12 : gel-purified $[22 \mathrm{GGG}]_{2}$. (e) P1 digestion of 22GGG hybridized to complementary strand 9C, linear $22 \mathrm{GGG}$ and $[22 \mathrm{GGG}]_{2}$, electrophoresed on a $12 \%$ denaturing polyacrylamide gel; digestions were performed in triplicate. Control lane: end-labelled 22GGG. (f) Data from e, quantified. Error bars represent s.d. of the mean of triplicates. LC indicates a ${ }^{32}$ P-labelled 100-nt oligonucleotide used as a control for loading and recovery.

components in $293 \mathrm{~T}_{\text {cells }}{ }^{40}$ and immunopurifying the assembled complex with an hTERT antibody ${ }^{41}$. The G-quadruplex [7GGT] $]_{4}$ was readily extended by human telomerase (Fig. 3a): the Michaelis-Menton constant $\left(K_{\mathrm{m}}\right)$ for $7 \mathrm{GGT}$ was $100 \pm 20 \mathrm{nM}$ and that for $[7 \mathrm{GGT}]_{4}$ was $500 \pm 120 \mathrm{nM}$ (mean \pm s.d.; $n=4-6$ ). Notably, both substrates supported equal amounts of catalytic activity, with a relative $V_{\max }$ (folded/linear) of $0.97 \pm 0.07$ (mean \pm s.d.; $P=0.3$, one-sample $t$-test; $n=7$ ).

There is a possibility that the one-step telomerase immunopurification method used in these experiments could allow co-immunopurification of other proteins that may selectively unwind the parallel G-quadruplexes, allowing the observed extension. To exclude this possibility, we purified human telomerase further with a four-step procedure involving immunopurification, capture onto an immobilized telomeric DNA substrate, release of active enzyme and sedimentation over a glycerol gradient ${ }^{42}$ (Fig. $3 \mathrm{~b}$ ); the specific activity of telomerase on an 18-nt telomeric substrate does not change over the course of purification (Supplementary Fig. 3). The purity of this telomerase was confirmed on a silver-stained SDS-polyacrylamide gel electrophoresis (PAGE) gel (Fig. 3b); the only visible protein bands correspond to the sizes of the core telomerase components hTERT and dyskerin ${ }^{42}$. The G-quadruplex helicase DHX36 (also known as G4R1 or RHAU) has been shown to associate with a portion of active telomerase in immortal human cells ${ }^{43,44}$; we confirmed this association in our 293T system by immunoblot analysis for DHX36 on one-step immunopurified telomerase (Fig. 3c). However, our four-step purification procedure resulted in loss of DHX36, confirmed by immunoblot of an equal molar amount of highly purified telomerase (GG in Fig. 3c).

Telomerase activity assays were performed with this highly purified telomerase alongside one-step immunopurified telomerase. The relative activity using $[7 \mathrm{GGT}]_{4}$ G-quadruplex and 7GGT linear DNA as substrates was the same for highly purified as for one-step purified telomerase (Fig. 3d). This confirms that the core telomerase enzyme complex is sufficient for extension of $[7 \mathrm{GGT}]_{4}$.

The dimeric parallel G-quadruplex $[22 \mathrm{GGG}]_{2}$ was also readily extended by immunopurified human telomerase, with a $K_{\mathrm{m}}$ of $53 \pm 10 \mathrm{nM}$ (Fig. 4a; mean \pm s.d.; $n=4$ ), under conditions in which we had demonstrated that this G-quadruplex is extremely stable. $[22 \mathrm{GGG}]_{2}$ was also extended by the highly purified telomerase preparation (Fig. 4b). Thus, the core human telomerase complex is capable of extending multiple parallel, intermolecular G-quadruplexes.

Obtaining reproducibly quantitative telomerase activity assays for linear $22 \mathrm{GGG}$ and $[22 \mathrm{GGG}]_{1}$ was confounded by the rapid interconversion between the folded and unfolded forms. It is well established that intramolecular, antiparallel G-quadruplexes are not good substrates for either ciliate or human telomerase ${ }^{22,23,39}$ 
a

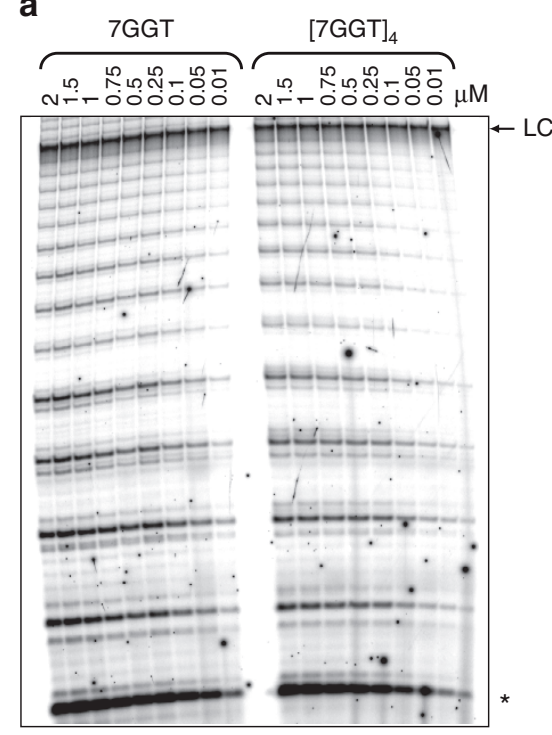

b

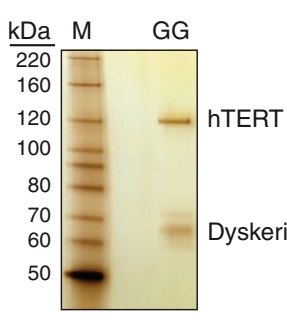

C

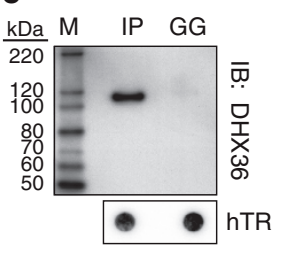

d

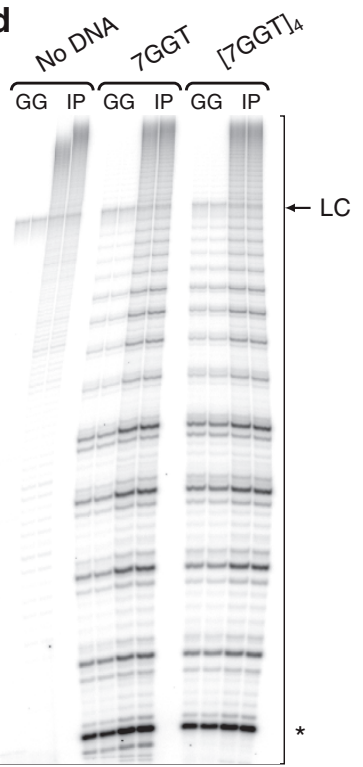

Figure 3 | Extension of $\mathbf{7 G G T}$ and $\left[\mathbf{7 G G T}_{\mathbf{4}}\right.$ by human telomerase. (a) Telomerase activity assays with immunopurified telomerase and the indicated concentrations of either $7 \mathrm{GGT}$ or $[7 \mathrm{GGT}]_{4}$. The concentrations of $[7 \mathrm{GGT}]_{4}$ refer to concentrations of the assembled, four-stranded G-quadruplex. (b) Silver-stained SDS-PAGE gel of highly purified telomerase (GG). (c) Immunoblot for DHX36 with immunopurified (IP) or highly purified (GG) telomerase. The bottom panel shows a dot-blot northern for hTR, demonstrating equal loading of telomerase in the gel. (d) Telomerase activity assays with $2 \mu \mathrm{M} 7 \mathrm{GGT}$ or [7GGT] 4 with immunopurified (IP) or highly purified (GG) telomerase, using equal amounts of each enzyme; reactions were performed in duplicate. For $\mathbf{a}$ and $\mathbf{d}$, the asterisk indicates the first visible addition product $(n+3)$; LC indicates a 32 P-labelled 100 -nt oligonucleotide used as a control for loading and recovery.

To confirm that this is also the case for the $[22 \mathrm{GGG}]_{1}$ intramolecular G-quadruplex folded in $\mathrm{Sr}^{2+}$, we again 'locked' linear 22GGG in $\mathrm{Sr}^{2+}$ into the unfolded form by hybridizing it with the complementary DNA oligonucleotide $9 \mathrm{C}^{39}$, which resulted in a twofold recovery of activity (Fig. $4 \mathrm{c}, \mathrm{d})$. In contrast, addition of the complementary strand to the $[22 \mathrm{GGG}]_{2}$ G-quadruplex did not affect activity (Fig. 4c,d). These data support our hypothesis that unfolded 22GGG is in equilibrium between linear and antiparallel G-quadruplex conformations, and confirm that the antiparallel $[22 \mathrm{GGG}]_{1}$ G-quadruplex is a less-favourable substrate for human telomerase than its linear counterpart. Taken together, these data demonstrate that multiple parallel, intermolecular G-quadruplexes are substrates for human telomerase, while an antiparallel, intramolecular G-quadruplex is not, despite the much higher stability of the former G-quadruplexes. We have also demonstrated that the core human telomerase enzyme complex is sufficient for parallel G-quadruplex extension.

Telomerase partially unwinds parallel G-quadruplexes. We have demonstrated that, for Tetrahymena telomerase, parallel G-quadruplex substrates increase the $K_{\mathrm{m}}$ of telomerase for the incoming dTTP nucleotide, presumably by perturbation of the nucleotide-binding site by the wider G-quadruplex substrate ${ }^{37}$. The $K_{\mathrm{m}}$ of human telomerase for dTTP was determined in the presence of saturating $[7 \mathrm{GGT}]_{4}$ G-quadruplex and 7GGT linear DNA at a range of dTTP concentrations (Fig. 5a). The $K_{\mathrm{m}}$ of telomerase for dTTP increased approximately fivefold in the presence of the G-quadruplex substrate, from $2.8 \pm 0.5 \mu \mathrm{M}$ for linear $7 \mathrm{GGT}$ to $15 \pm 5 \mu \mathrm{M}$ with $[7 \mathrm{GGT}]_{4}$ (mean \pm s.d.; $P=0.0136$, unpaired two-tailed $t$-test; $n=3$ ). This change in $K_{\mathrm{m}}$ provides evidence that the observed extension is occurring with two conformationally distinct substrates.

We demonstrated the maintenance of G-quadruplex structure following telomerase extension directly, by visualizing telomerase extension products by native gel electrophoresis. A mixture of unlabelled $[22 \mathrm{GGG}]_{1}$ and $[22 \mathrm{GGG}]_{2}$ was extended by telomerase in the presence of $\left[\alpha^{32} \mathrm{P}\right]$-dTTP (Fig. 5b,c). Under native gel electrophoresis conditions, a single band was present following telomerase extension (Fig. 5c, lane 3) that aligns with an authentic ${ }^{32} \mathrm{P}$-labelled $[22 \mathrm{GGG}]_{2}$ marker (Fig. $5 \mathrm{c}$, lane 2). These data provide evidence that the $[22 \mathrm{GGG}]_{2}$ parallel G-quadruplex structure is maintained following extension by telomerase. Direct observation of $[22 \mathrm{GGG}]_{2}$ specifically labelled through extension by telomerase provides unequivocal evidence that G-quadruplex DNA must be the substrate utilized by telomerase.

The telomerase RNA template hybridizes to telomeric DNA to enable telomere extension with the correct alignment. Ciliate telomerase can perform extension of non-telomeric substrates without any complementarity between the DNA primer and RNA template, using a specific template position as the default for the initiation of extension ${ }^{26}$. We wished to test whether the extension of parallel G-quadruplexes is preceded by canonical template hybridization (Fig. 5b). We performed telomerase activity assays in the presence of different combinations of nucleotides, for both $[7 \mathrm{GGT}]_{4}$ and [22GGG] $]_{2}$ (Fig. 5d,e). A standard processive reaction including $\left[\alpha-{ }^{32} \mathrm{P}\right]-\mathrm{dGTP}$, dATP and dTTP provided a marker for band positions, as the major pause site in a processive reaction is at the end of the template (products ending in -TAG; see labelling of gel in Fig. 5d,e). In the presence of only $\left[\alpha-{ }^{32} \mathrm{P}\right]-\mathrm{dTTP}$ and dATP, we anticipated the addition of two nucleotides (TA) and three nucleotides (TTA) to primers 7GGT and 22GGG, respectively, if the terminal $3^{\prime}$ nucleotides are correctly aligning with the RNA template (Fig. 5b). Because addition of ddGTP results in termination of DNA strand elongation, we anticipated the addition of three nucleotides (TAG) and four nucleotides (TTAG) to 7GGT and 22GGG, respectively, in the presence of $\left[\alpha^{-}{ }^{32} \mathrm{P}\right]-\mathrm{dTTP}, \mathrm{dATP}$ and ddGTP. In all cases, the patterns of extension of parallel G-quadruplexes $[7 \mathrm{GGT}]_{4}$ and $[22 \mathrm{GGG}]_{2}$ are identical to their respective linear 
a
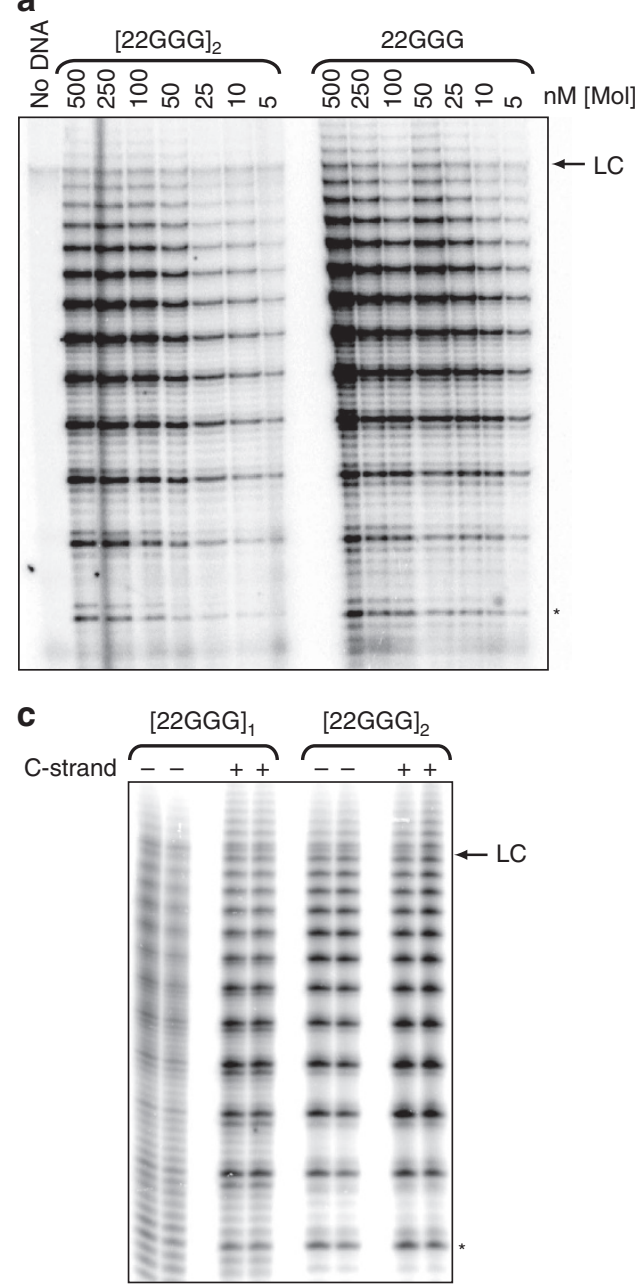

b

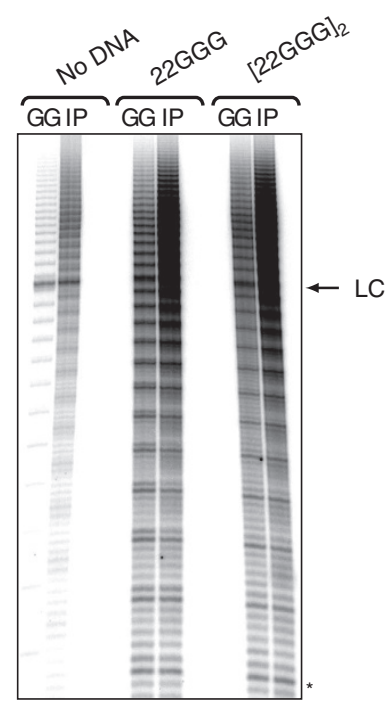

d

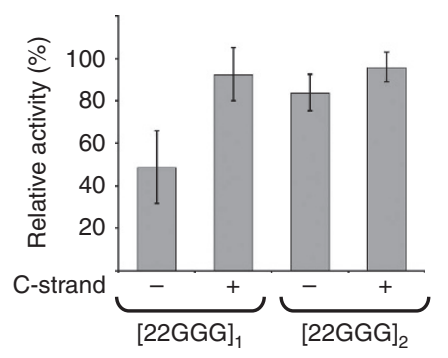

Figure 4 | Extension of linear 22GGG and [22GGG] $\mathbf{2}_{\mathbf{2}}$, but not [22GGG] $\mathbf{1}_{\mathbf{1}}$ by human telomerase. (a) Telomerase activity assays with immunopurified telomerase and the indicated concentrations of either linear 22GGG or [22GGG]2. (b) Telomerase activity assays with $1 \mu \mathrm{M}$ linear $22 \mathrm{GGG}$ or $[22 \mathrm{GGG}]_{2}$ with immunopurified (IP) or highly purified (GG) telomerase, using equal amounts of each enzyme. (c) Telomerase activity assays with immunopurified telomerase and $1 \mu \mathrm{M}[22 \mathrm{GGG}]_{1}$ and $[22 \mathrm{GGG}]_{2}$, with or without complementary strand $9 \mathrm{C}$ as indicated; reactions were performed in duplicate.

(d) Quantification of $\mathbf{c}$ normalized against 22GGG pre-annealed with 9C. Error bars represent s.d. of the mean of three independent experiments. In all panels, the asterisk indicates the first visible addition product $(n+4)$, and LC indicates a ${ }^{32}$ P-labelled 100-nt oligonucleotide used as a control for loading and recovery.

controls (Fig. 5d,e) and correspond with expected nucleotide addition patterns (Fig. 5b). For canonical hybridization to occur, at least a portion of the parallel G-quadruplex structure must be unwound. As native gel electrophoresis demonstrated alignment of the extended parallel G-quadruplex with an identical ${ }^{32}$ P-labelled marker (Fig. 5c), we conclude that parallel G-quadruplexes are partially unwound to allow hybridization of the telomerase template with the $3^{\prime}$ end of the DNA.

Telomerase localizes to G-quadruplex-containing telomeres. To investigate the presence of parallel telomeric G-quadruplexes in cells, we performed immunofluorescence on human embryonic kidney $293 \mathrm{~T}$ cells using a G-quadruplex-specific antibody ${ }^{18}$. Fixed cells were subjected to cytoplasmic extraction prior to immunofluorescence to remove RNA G-quadruplexes; a DNasetreated control demonstrates the specificity of the antibody for DNA G-quadruplexes under these conditions (Fig. 6a, top right). A subset of telomeres colocalized with G-quadruplex foci (Fig. 6a, top panel), as previously demonstrated ${ }^{18}$. Treatment of the cells with the parallel-specific G-quadruplex porphyrin ligand $N$-methyl mesoporphyrin $\mathrm{IX}^{45-47}$ (Supplementary Fig. 4a) during
mid-S phase of the cell cycle resulted in an increase in the number of G-quadruplex-telomere colocalizations per cell (Fig. 6a,b), without affecting progression of the cells into mid-S phase (Supplementary Fig. 4b). These data provide evidence that parallel G-quadruplexes can form at human telomeres in vivo.

Since human telomerase can extend parallel G-quadruplexes in vitro, we asked whether telomeric G-quadruplexes are a site of localization for human telomerase in vivo. $293 \mathrm{~T}$ cells were synchronized in mid-S phase, which is the peak of telomerase recruitment to telomeres ${ }^{48}$. Using G-quadruplex immunofluorescence, combined with fluorescence in situ hybridization (FISH) for telomerase RNA (hTR) and telomeres ${ }^{49}$, we observed the simultaneous colocalization of endogenous telomerase, G-quadruplexes and telomeres (Fig. 6c; Supplementary Fig. 5). Control experiments demonstrate that depletion of dyskerin, a component of the core telomerase complex ${ }^{42}$, markedly reduces hTR foci, verifying the specificity of the FISH signal (Supplementary Fig. 6). G-quadruplex foci colocalized with $\sim 17 \%$ of total hTR-telomere foci (Fig. 6d). These results reveal that human telomerase can localize to telomeres at which G-quadruplexes are present. 
a

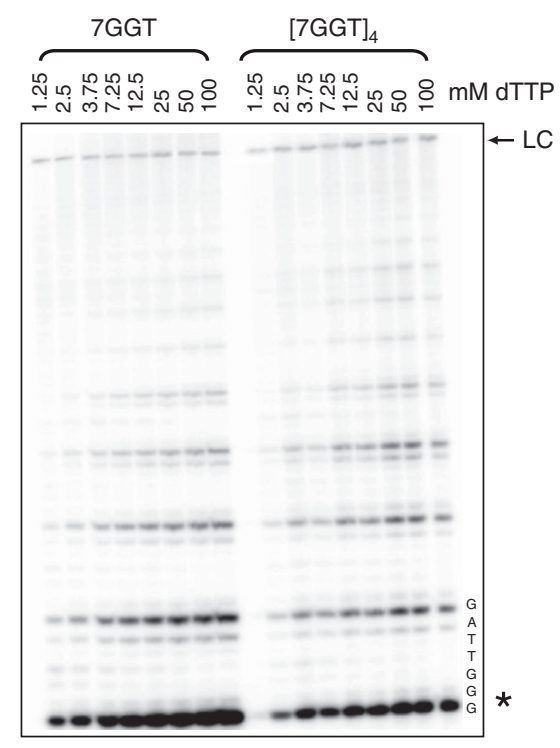

d

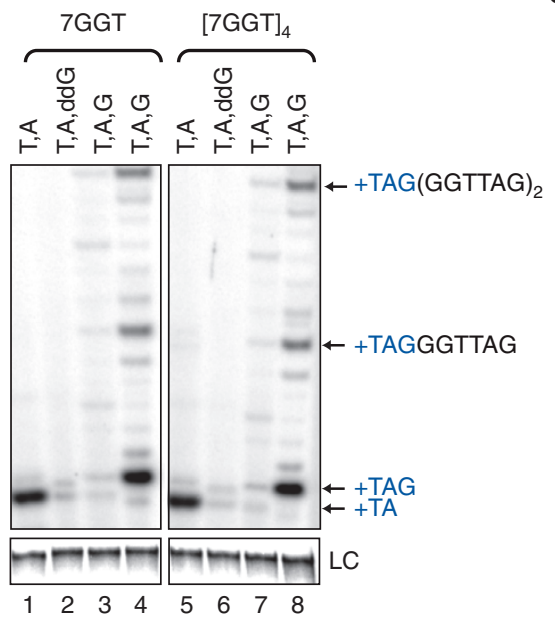

b

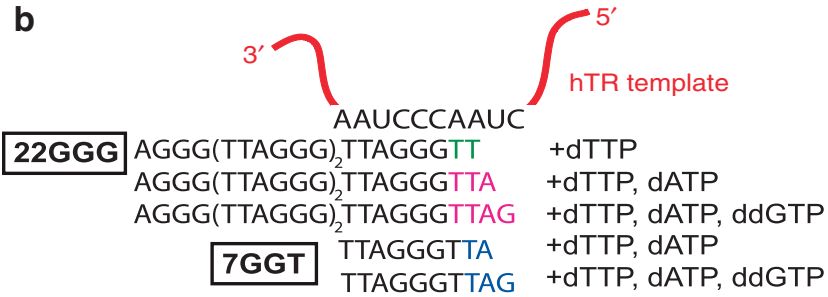

C

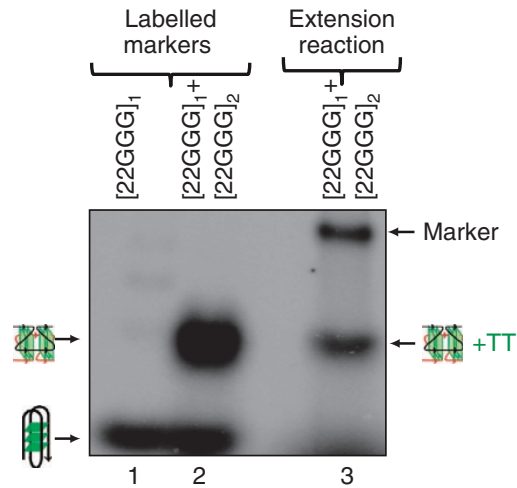

e

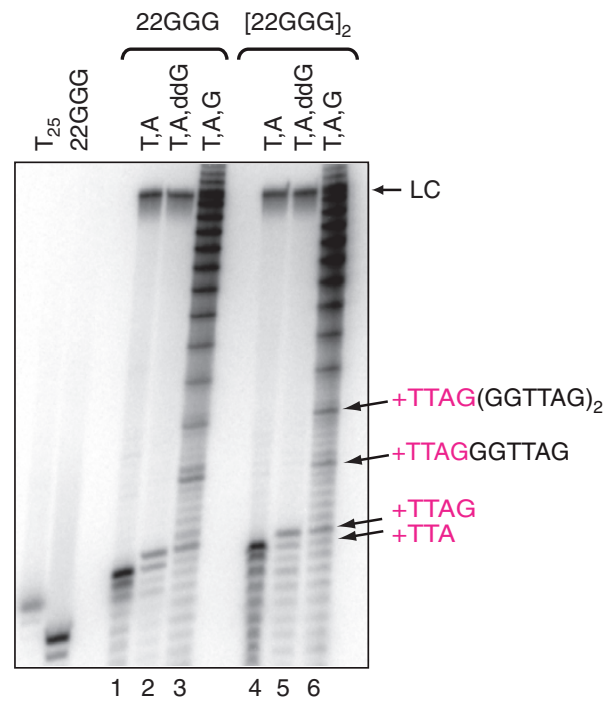

Figure 5 | Telomerase partially unwinds and extends [7GGT] $\mathbf{4}_{\mathbf{4}}$ and [22GGG] $]_{\mathbf{2}}$. (a) Telomerase activity assays with immunopurified telomerase, using $1 \mu \mathrm{M} 7 \mathrm{GGT}$ or $[7 \mathrm{GGT}]_{4}$ and the indicated concentrations of dTTP. The asterisk indicates the first visible addition product $(n+3)$. $(\mathbf{b})$ Expected telomerase products upon alignment of 7GGT or 22GGG with the RNA template in the presence of different combinations of nucleotides. (c) Telomerase activity assay followed by native gel electrophoresis. Lane 1: $5^{\prime}$-end-labelled $[22 \mathrm{GGG}]_{1}$. Lane 2: mixture of $5^{\prime}$-end-labelled $[22 \mathrm{GGG}]_{1}$ and $[22 \mathrm{GGG}]_{2}$, demonstrating separation of the two species. Lane 3: products of unlabelled $[22 \mathrm{GGG}]_{1}$ and $[22 \mathrm{GGG}]_{2}$ following telomerase extension in the presence of $[\alpha-32 \mathrm{P}]-\mathrm{dTTP}$. Unstructured marker added for orientation purposes. (d) Templated addition of nucleotides to 7GGT and [7GGT] 4 . G-quadruplexes and their linear counterparts $(2 \mu \mathrm{M})$ were incubated with telomerase in the presence of: lanes 1 and 5: ${ }^{32} \mathrm{P}$-dTTP and dATP; lanes 2 and $6:{ }^{32} \mathrm{P}$-dTTP, dATP and ddGTP; lanes 3 and 7: ${ }^{32} \mathrm{P}-\mathrm{dTTP}, \mathrm{dATP}$ and dGTP; lanes 4 and 8: dTTP, dATP and ${ }^{32} \mathrm{P}$-dGTP, and products electrophoresed on a denaturing $12 \%$ acrylamide gel. Migration position of different products is shown. (e) Templated addition of nucleotides to 22GGG and [22GGG]2. G-quadruplexes and their linear counterparts $(2 \mu \mathrm{M})$ were incubated with telomerase in the presence of: lanes 1 and $4:{ }^{32} \mathrm{P}$-dTTP and ddATP; lanes 2 and 5: ${ }^{32} \mathrm{P}$-dTTP, dATP and ddGTP; lanes 3 and 6: dTTP, dATP and ${ }^{32}$ P-dGTP, and products electrophoresed on a denaturing $12 \%$ acrylamide gel. End-labelled $T_{25}$ and 22 GGG markers are on the left of the gel. Migration position of different products is shown. In all panels, LC indicates a ${ }^{32}$ P-labelled 100-nt oligonucleotide used as a control for loading and recovery.

\section{Discussion}

It has been hypothesized that G-quadruplexes can sequester the $3^{\prime}$ end of the telomere and prevent it from being extended by telomerase ${ }^{22,39}$. Here, we demonstrate that parallel intermolecular telomeric G-quadruplexes are partially unwound and robustly extended by human telomerase. We used highly purified telomerase to show that the core telomerase enzyme complex has the ability to partially unwind the G-quadruplexes prior to their extension.

The apparent affinity of telomerase for the incoming dTTP nucleotide was significantly reduced when extending $[7 \mathrm{GGT}]_{4}$ compared with linear 7GGT, suggesting a change in the conformation of (or near) the active site of telomerase to accommodate the wider G-quadruplex structure. This difference 
a
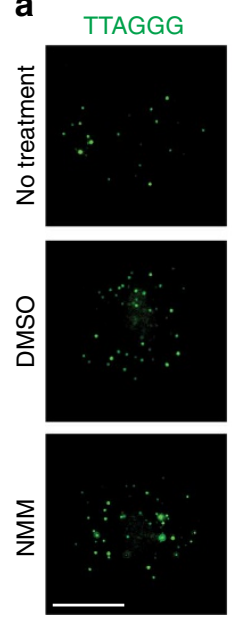

C TTAGGG

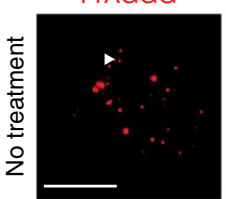

G4
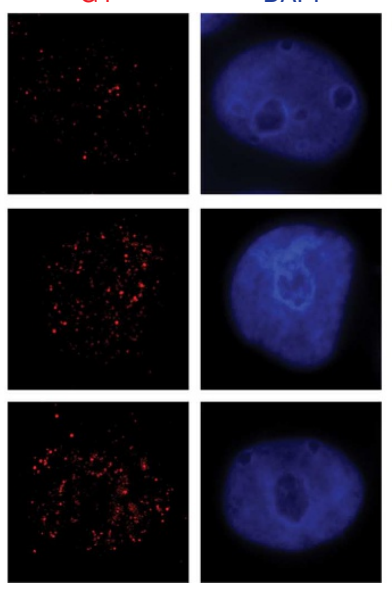

G4

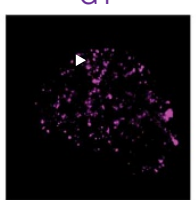

hTR

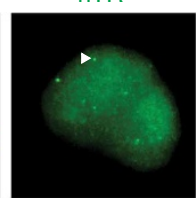

Merge
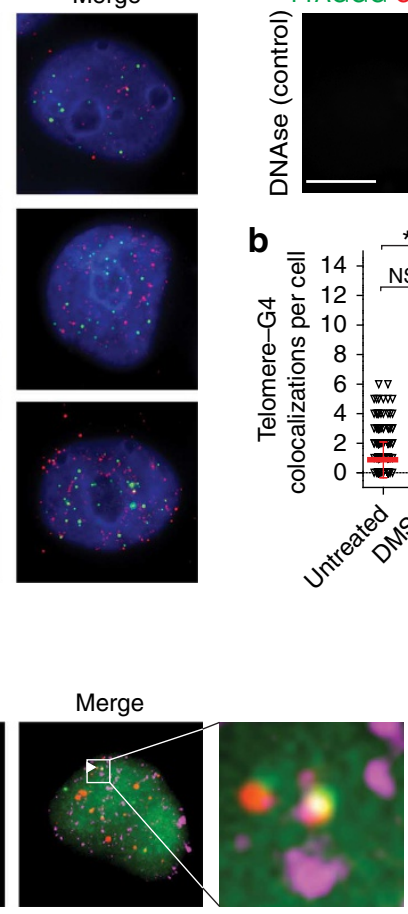
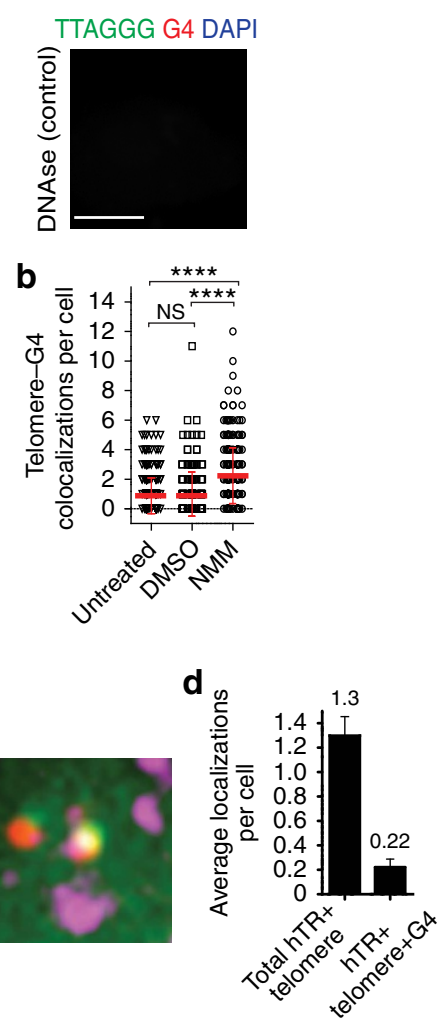

Figure 6 | G-quadruplex-containing telomeres are a site of localization for human telomerase. (a) Immunofluorescence with G-quadruplex antibody BG4 together with telomere FISH, in mid-S-phase HEK 293T cells with no treatment (top), vehicle (dimethyl sulfoxide (DMSO), middle) or parallel-specific ligand $\mathrm{N}$-methyl mesoporphyrin IX (NMM) (bottom). DNAse treatment is included as a G-quadruplex antibody control (top right). (b) Quantification of number of telomere-G-quadruplex colocalizations per cell from a. One hundred nuclei were counted per condition in two (DMSO) or three (untreated and NMM) independent experiments. Error bars represent the s.e.m. Statistical significance was calculated using an unpaired $t$-test; ${ }^{\star \star \star \star} P<0.0001$ (c) Immunofluorescence with G-quadruplex antibody BG4 together with FISH for telomeres and telomerase RNA (hTR). (d) Quantification of hTR-telomere-BG4 trilocalization frequency, relative to telomerase-telomere localization events. Hundred nuclei were counted in each of the three independent experiments. Error bars represent the s.e.m. Scale bars, $10 \mu \mathrm{m}$. NS, not significant.

of $K_{\mathrm{m}}$ with different conformations of DNA substrate demonstrates that the parallel G-quadruplex is a substrate for telomerase while still at least partially structured, an observation we confirmed using native gel electrophoresis of a parallel G-quadruplex following extension (Fig. 5c). Nevertheless, the telomerase extension patterns demonstrate correct alignment of the $3^{\prime}$ end of the DNA substrate with the RNA template, indicating that parallel G-quadruplexes are partially unwound by or invaded by telomerase. Neither of the parallel G-quadruplexes in this study demonstrated any hybridization to a complementary DNA oligonucleotide or digestion by a nuclease under the conditions of the telomerase activity assays, arguing against a model of spontaneous transient unfolding of the DNA $3^{\prime}$ ends followed by telomerase extension. Given the exceptional stability of the $[22 \mathrm{GGG}]_{2} \mathrm{G}$-quadruplex, in particular, these data support an extension model where the parallel G-quadruplex structure is bound and subsequently partially resolved by telomerase prior to extension of the DNA $3^{\prime}$ end (Fig. 7). We are currently investigating the mechanism of this resolution, including the regions of telomerase responsible, given that neither hTERT nor dyskerin contains a known helicase domain. It is possible that telomerase uses a similar mechanism as that proposed for replication protein $\mathrm{A}$, involving binding to the single-stranded loop regions between stacks of G-quartets ${ }^{50}$.

Currently, there are a large number of laboratories investigating the interactions of stabilizing ligands with G-quadruplexes. It is therefore crucial to determine the specificity of human

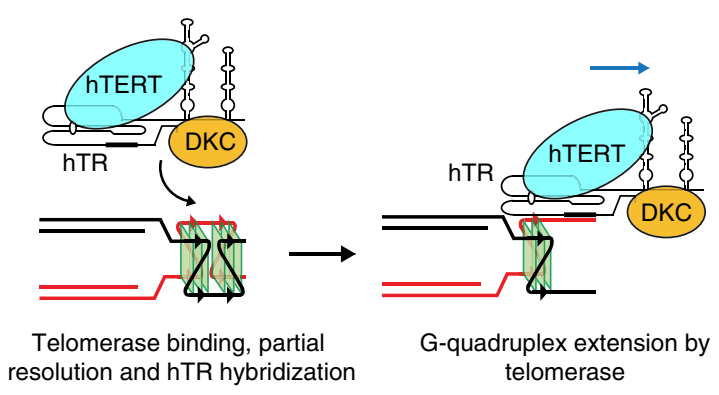

Figure 7 | Proposed model for telomerase action at telomeric G-quadruplexes. Telomerase binds to a parallel G-quadruplex structure. The core telomerase complex is then able to partially unwind the G-quadruplex allowing hybridization of the RNA template and DNA extension.

telomerase for the different conformations of G-quadruplexes, such that once the in vivo structure(s) of human telomeres is determined, suitable G-quadruplex-stabilizing ligands of appropriate specificity can be rationally selected. Although in vivo evidence for G-quadruplex structures is increasing, the structure-specific locations and functions of G-quadruplexes remain speculative. Our in vivo data indicate that parallel G-quadruplexes can form at human telomeres, and that telomeres containing a G-quadruplex are a site of localization for human telomerase. That telomerase is also able to partially unwind and 
extend these structures, and the evolutionary conservation of this property in distantly related organisms such as Tetrahymena ${ }^{23}$, implies that telomeric DNA in a parallel G-quadruplex conformation may have a biological role. In support of this idea, it has been demonstrated that promotion of parallel telomeric G-quadruplexes by the Saccharomyces cerevisiae protein Estlp is essential for telomerase-mediated telomere elongation in that organism ${ }^{51}$. One potential biological role for telomeric G-quadruplexes in human cells may be during meiosis, when two pairs of sister chromatids are brought together; it has been suggested that parallel G-quadruplexes could be responsible for the correct alignment of the four chromatids ${ }^{52}$. The ability of telomerase to partially unwind and extend parallel G-quadruplexes potentially formed during meiosis may be necessary for the maintenance of germline telomere length. Alternatively, G-quadruplexes may be involved in the association of telomeres of sister chromatids during $\mathrm{S}$ phase, which is known to be necessary for telomerase to lengthen telomeres in human cells ${ }^{53}$. The data presented here provide evidence that subtypes of telomeric G-quadruplexes interact differentially with human telomerase, possibly reflecting their different biological roles.

\section{Methods}

Oligonucleotide preparation. DNA oligonucleotides (Table 1) were purchased from Sigma Genosys in desalted form. All oligonucleotides were purified by electrophoresis on denaturing $20 \%$ polyacrylamide $/ 8 \mathrm{M}$ urea gels in $1 \times$ TBE buffer ( $89 \mathrm{mM}$ Tris, $89 \mathrm{mM}$ borate and $2 \mathrm{mM}$ EDTA). The major band was excised and eluted by crushing and soaking for $12-16 \mathrm{~h}$ at $4{ }^{\circ} \mathrm{C}$ with rotation in TEK $(10 \mathrm{mM}$ Tris- $\mathrm{HCl}, \mathrm{pH} 7.5-8.0,1 \mathrm{mM}$ EDTA and $250 \mathrm{mM} \mathrm{KCl})$ for 7GGT and TESr (10 mM Tris- $\mathrm{HCl}, \mathrm{pH} 7.5-8.0,1 \mathrm{mM}$ EDTA and $250 \mathrm{mM} \mathrm{SrCl}_{2}$ ) for $22 \mathrm{GGG}$, and ethanol precipitated for $2-16 \mathrm{~h}$ at $-20^{\circ} \mathrm{C}$. The precipitated product was resuspended in $10 \mathrm{mM}$ Tris-Cl, $\mathrm{pH} 7.5$.

G-quadruplex formation and purification. 7GGT (1 mM) or 22GGG (700 $\mu \mathrm{M})$ were heat denatured in $\mathrm{K}^{+}$hTel buffer $\left(50 \mathrm{mM}\right.$ Tris- $\mathrm{HCl}, \mathrm{pH} 8.0,1 \mathrm{mM} \mathrm{MgCl}_{2}$ and $150 \mathrm{mM} \mathrm{KCl}$ ) or $\mathrm{Sr}^{2+}$ hTel buffer (50 mM Tris- $\mathrm{HCl}, \mathrm{pH} 8.0,1 \mathrm{mM} \mathrm{MgCl}_{2}$ and $2.5 \mathrm{mM} \mathrm{SrCl}_{2}$ ), respectively, for $5 \mathrm{~min}$ at $95^{\circ} \mathrm{C}$. They were allowed to cool slowly $(\sim 1 \mathrm{~h})$ to $25^{\circ} \mathrm{C}$ and left to equilibrate at this temperature for $72 \mathrm{~h}$. The folded DNA was added to $6 \times$ native gel loading buffer $(0.25 \%$ bromophenol blue, $0.25 \%$ xylene cyanol and $30 \%$ glycerol). 7GGT was electrophoresed on a non-denaturing $12 \%$ polyacrylamide gel containing $150 \mathrm{mM} \mathrm{KCl}$ for $4.5 \mathrm{~h}$ at $12 \mathrm{~W}$ at $22^{\circ} \mathrm{C}$. $22 \mathrm{GGG}$ was electrophoresed on a non-denaturing $12 \%$ polyacrylamide gel containing $2.5 \mathrm{mM} \mathrm{SrCl}_{2}$ for $24 \mathrm{~h}$ at $40 \mathrm{~V}$ at $18^{\circ} \mathrm{C}$. Both buffer and gel contained the same constituents as the DNA-folding buffer. Ultraviolet shadowing was used to confirm the location of the DNA bands on the gel. The band of interest was excised and crushed in either TEK (7GGT) or TESr (22GGG) and incubated for $2-16 \mathrm{~h}$ at $4{ }^{\circ} \mathrm{C}$ with rotation. The supernatant was filtered $(0.22 \mu \mathrm{m})$ and the DNA precipitated with ethanol for $2-16 \mathrm{~h}$ at $-20^{\circ} \mathrm{C}$. The precipitated product was resuspended in the original folding buffer. DNA concentrations were determined by ultraviolet absorbance at $260 \mathrm{~nm}$ (7GGT: $69,800 \mathrm{M}^{-1} \mathrm{~cm}^{-1}$; 22GGG: $228,500 \mathrm{M}^{-1} \mathrm{~cm}^{-1}$; 9C: $76,500 \mathrm{M}^{-1} \mathrm{~cm}^{-1}$ ). Concentrations of G-quadruplexes are given as the concentration of assembled complexes (that is, taking strand stoichiometry into account). Folded G-quadruplexes were stored at $4{ }^{\circ} \mathrm{C}$ until use.

In some experiments, oligonucleotides were $5^{\prime}$-end-labelled with $\left[\gamma_{-}{ }^{32} \mathrm{P}\right] \mathrm{ATP}$ prior to G-quadruplex formation and purification, as described ${ }^{23}$. Radiolabelled structures were used for some native gel analyses (for example, Fig. 1a), and P1 digestion assays, at $10-15 \times 10^{3}$ c.p.m. per gel lane, whereas unlabelled G-quadruplexes were used for telomerase assays, CD analysis and other native gel analyses (for example, Fig. 1c). In the latter experiment, $250 \mathrm{ng}$ of each DNA was electrophoresed on a non-denaturing $12 \%$ polyacrylamide gel, which was stained in $1 \times$ SYBR Gold (Life Technologies) at $25^{\circ} \mathrm{C}$ for $30 \mathrm{~min}$, and visualized on a Typhoon FLA9500 scanner (GE Healthcare Lifesciences) using a 488-nm laser and a 526 BP emission filter.

Circular dichroism. CD spectra were recorded at $25^{\circ} \mathrm{C}$ on a Jasco J-810 spectrometer or an Aviv 215S CD spectrometer equipped with a Peltier temperature controller. G-quadruplex samples of the desired conformation were prepared at $20 \mu \mathrm{M}$ in corresponding hTel buffers. Four scans were accumulated over the wavelength range $220-320 \mathrm{~nm}$ in a $0.1-\mathrm{cm}$ pathlength cell at standard sensitivity, data pitch $0.1 \mathrm{~nm}$, continuous scanning mode, scanning speed $100 \mathrm{~nm} \mathrm{~min}^{-1}$, response $4 \mathrm{~s}$ and bandwidth $1 \mathrm{~nm}$. Buffers alone were also scanned and these spectra subtracted from the average scans for each sample. CD spectra were collected in units of millidegrees, normalized to the total species concentrations and expressed as molar ellipticity units $\left(\mathrm{deg} \times \mathrm{cm}^{2} \mathrm{dmol}^{-1}\right)$.

Electrospray ionization mass spectrometry. All ESI mass spectra were obtained using a Waters Q-TOF Ultima ESI mass spectrometer (Manchester, UK). Purified G-quadruplex samples were dissolved in $150 \mathrm{mM} \mathrm{NH}_{4} \mathrm{OAc}$ at a concentration of $20 \mu \mathrm{M}$. In all experiments the capillary voltage $(2.2 \mathrm{kV})$, cone voltage $(35 \mathrm{~V})$, desolvation temperature $\left(40^{\circ} \mathrm{C}\right)$, radio frequency lens $(65 \mathrm{~V})$, desolvation gas flow $\left(150 \mathrm{l} \mathrm{h}^{-1}\right)$, collision energy $(4 \mathrm{~V})$, cone gas flow $\left(0.0021 \mathrm{lh}^{-1}\right)$ and TOF $(9.1 \mathrm{kV})$ remained the same. All spectra were obtained in the negative ion mode. The instrument was calibrated using $1 \mathrm{mg} \mathrm{ml}^{-1}$ caesium iodide. Samples were injected at a flow rate of $10 \mu \mathrm{min}^{-1}$ with a Harvard Model 22 syringe pump (Natick, USA).

Complementary C-strand trap assay. This method was carried out using a modified procedure to that published ${ }^{37,38}{ }^{32} \mathrm{P}$-labelled gel-purified [7GGT] $]_{4}$ (3,000 c.p.m. $\left.\mu \mathrm{l}^{-1}, 4 \mu \mathrm{M}\right)$ or unlabelled $[22 \mathrm{GGG}]_{2}(2.5 \mu \mathrm{M})$ were incubated in the presence of a 10 -fold excess of $9 \mathrm{C}$ (Table 1 ) at $30^{\circ} \mathrm{C}$ to give a final reaction volume of $28 \mu \mathrm{l}$. Aliquots $(4 \mu \mathrm{l})$ of this hybridization reaction were removed at regular time intervals and loaded onto a native $12 \%$ polyacrylamide gel containing $150 \mathrm{mM}$ $\mathrm{KCl}\left([7 \mathrm{GGT}]_{4}\right)$ or a native $16 \%$ polyacrylamide gel containing $2.5 \mathrm{mM}$ $\mathrm{SrCl}_{2}\left([22 \mathrm{GGG}]_{2}\right)$, with the gel running continuously between time points. Electrophoresis was conducted as described above. For complementary C-strand trap assays with increasing $9 \mathrm{C}$ concentrations, ${ }^{32} \mathrm{P}$-labelled gel-purified [7GGT] was incubated at $11 \mu \mathrm{M}$ in the presence of a 5-, 10-, 25- or 100-fold excess of 9C at either $30^{\circ} \mathrm{C}$ or $37^{\circ} \mathrm{C}$. For $[7 \mathrm{GGT}]_{4}$, the gel was dried at $80^{\circ} \mathrm{C}$ for $40 \mathrm{~min}$, exposed to a PhosphorImager screen, visualized on a Typhoon FLA9500 scanner and analysed using ImageQuant software. For $[22 \mathrm{GGG}]_{2}$, the gel was stained with SYBR Gold at $25^{\circ} \mathrm{C}$ for $30 \mathrm{~min}$, visualized on a Typhoon FLA9500 scanner and analysed using ImageQuant software. Uncropped versions of blots are provided in Supplementary Fig. 7.

Phosphodiesterase 1 digestion of G-quadruplexes. ${ }^{32} \mathrm{P}$-end-labelled [7GGT] $]_{4}$ or [22GGG $]_{2}$ (15,000 c.p.m.) and their linear controls were incubated with $2 \mu \mathrm{g} \mathrm{P1}$ (Affymetrix; resuspended in $110 \mathrm{mM}$ Tris- $\mathrm{HCl}, \mathrm{pH} 8.9,110 \mathrm{mM} \mathrm{NaCl}, 15 \mathrm{mM}$ $\mathrm{MgCl}_{2}$ and $50 \%$ glycerol) in hTel buffer (as listed above) for $1 \mathrm{~h}$ at $30^{\circ} \mathrm{C}$ in a total reaction volume of $20 \mu \mathrm{l}$. The reaction was terminated with $80 \mu \mathrm{l}$ of stop-buffer (50 mM Tris-HCl, pH 8.3, 20 mM EDTA, $0.2 \%$ SDS and $1-2 \times 10^{3}$ c.p.m. of a $5^{\prime}-{ }^{32} \mathrm{P}$-labelled synthetic 100 -mer DNA as an internal recovery standard). From this point, the samples were treated in the same manner as 'telomerase activity assay' reactions (see below).

HEK293T fermentation and telomerase overexpression. HEK293T cells (from Dr Timothy Adams, Commonwealth Scientific and Industrial Research Organisation) were adapted to grow in suspension in Freestyle 293 Expression medium (Life Technologies) supplemented with $200 \mathrm{mgl}^{-1} \mathrm{G} 418$ (Life Technologies) using a humidified shaker incubator $\left(37^{\circ} \mathrm{C}, 5 \% \mathrm{CO}_{2}, 130\right.$ r.p.m. $)$. The adapted HEK293T culture was maintained in Erlenmeyer shaker flasks and scaled up in a 20-1 WAVE bioreactor (GE Healthcare), seeded at an initial working volume of $5 \mathrm{l}$ at a concentration of $0.8 \times 10^{6}$ viable cells per ml. To reduce shear stress, Pluronic F86 (Life Technologies) was added to the culture at $0.2 \% \mathrm{w} / \mathrm{v}$ final concentration. The culture was scaled up to $20 \mathrm{l}$ at a viable cell density of $3 \times 10^{6}$ cells per $\mathrm{ml}$, at which time transient transfection was initiated. The hTERT gene ${ }^{54}$ under a CMV promoter was cloned into plasmid pAPEX-3P ${ }^{40,55}$. The hTR gene under a U3 promoter ${ }^{56}$ and dyskerin (OriGene Technologies) under a CMV promoter were cloned into a single plasmid in vector pAPEX-3 (ref. 55). Plasmids were produced on the 200-mg scale by GenScript (USA) and used at an hTERT:hTR ratio of 1:19 by weight. Polyethylenimine ( $25 \mathrm{kDa}$ linear, Polysciences) was prepared as an aqueous solution at $1 \mathrm{mg} \mathrm{ml}^{-1}$ at $\mathrm{pH} 7.0$ and filter-sterilized $(0.22 \mu \mathrm{m})$. Per litre of culture, a transfection mix was prepared by adding $1 \mathrm{mg}$ DNA to $100 \mathrm{ml}$ PBS pre-warmed to $37^{\circ} \mathrm{C}$, followed by addition of $4 \mathrm{ml}$ polyethylenimine solution; the solution was mixed gently and incubated at room temperature (RT) for 15 min prior to addition to the 20 -l culture, which was maintained at $37^{\circ} \mathrm{C}$ with a rocking speed of 25 r.p.m. and rocking angle of $9^{\circ}$. At 2 days after transfection, the culture was fed with $5 \mathrm{gl}^{-1}$ Lupin (Cell Biosciences), $2 \mathrm{mM}$ Glutamax-1 (Life Technologies) and $5 \mathrm{gl}^{-1}$ glucose (Sigma), and the temperature was reduced to $32^{\circ} \mathrm{C}$. The cells were harvested 4 days after transfection by centrifugation $\left(1,500 \mathrm{~g}, 10 \mathrm{~min}, 4^{\circ} \mathrm{C}\right)$, snap-frozen on liquid nitrogen and stored at $-80^{\circ} \mathrm{C}$. Telomerase high-expressing HEK293T cell pellets are available from Abbexa Ltd, Cambridge, UK.

Purification of overexpressed 293T telomerase. Approximately $130 \mathrm{~g} 293 \mathrm{~T}$ cell mass $\left(\sim 4 \times 10^{10}\right.$ cells) was broken up to a paste in a $1-1$ plastic beaker. The cell paste was suspended in $800 \mathrm{ml}$ ice-cold lysis buffer (10 mM HEPES-KOH (pH 8.0), $20 \mathrm{mM} \mathrm{KCl}, 2 \mathrm{mM} \mathrm{MgCl} 2,1 \% \mathrm{v} / \mathrm{v}$ Triton X-100, $1 \mathrm{mM}$ dithiothreitol (DTT)). Once suspended, $8 \mathrm{ml}$ of phenylmethylsulfonyl fluoride solution $(100 \mathrm{mM}$ in ethanol, made fresh) was added with stirring. The suspension was transferred in 50-ml portions to a $50-\mathrm{ml}$ Dounce homogenizer with a tight pestal on ice and processed 
to ensure complete dissolution of cell paste, then pooled into a 1-1 bottle equipped with magnetic stir bar. The lysate was stirred on ice for $1 \mathrm{~h}$, then divided between four 250-ml bottles for the Beckman JA-14 rotor. The lysate was clarified with centrifugation at 14,000 r.p.m. $(\sim 30,000 \mathrm{~g})$ at $2{ }^{\circ} \mathrm{C}$ for $30 \mathrm{~min}$. The clear lysate $(\sim 850 \mathrm{ml})$ was collected into a 1-1 bottle equipped with magnetic stirrer. With stirring on ice, $22 \mathrm{ml}$ of $2 \mathrm{M} \mathrm{MgCl}_{2}\left(\sim 50 \mathrm{mM}\right.$ final $\left.\mathrm{Mg}^{2+}\right)$ was added and the suspension was stirred for $1 \mathrm{~h}$ to selectively precipitate ribonucleoprotein complexes $^{57}$. The suspension was divided between four $250-\mathrm{ml}$ bottles for the Beckman JA-14 rotor, and the products were collected with centrifugation at 10,000 r.p.m. $(\sim 15,000 \mathrm{~g})$ at $2{ }^{\circ} \mathrm{C}$ for $30 \mathrm{~min}$. The supernatant was decanted to provide white pellets. Each pellet was suspended in $50 \mathrm{ml}$ immunoprecipitation (IP) buffer ( $50 \mathrm{mM}$ HEPES-KOH (pH 8.0), $500 \mathrm{mM} \mathrm{KCl}, 2 \mathrm{mM} \mathrm{MgCl}_{2}, 1 \% \mathrm{v} / \mathrm{v}$ Triton X-100, $10 \% \mathrm{v} / \mathrm{v}$ glycerol and $1 \mathrm{mM} \mathrm{DTT}$ ). To aid dissolution, the suspension was processed through a Dounce homogenizer with a tight pestal on ice until a slightly white, homogeneous solution was obtained. The material was pooled into a $500-\mathrm{ml}$ bottle on ice, and the volume was made up to $300 \mathrm{ml}$ with additional IP buffer. Polyclonal hTERT antibody (raised against hTERT amino acids 276-294 (ARPAEEATSLEGALSGTRH) ${ }^{41}$; available from Abbexa Ltd) $\left(12 \mathrm{mg}=40 \mu \mathrm{g} \mathrm{ml}^{-1}\right.$ final concentration) was added and the solution shaken on ice for $30 \mathrm{~min}$. To capture the antibody-telomerase complex, $12 \mathrm{ml}$ of a $50 \% \mathrm{v} / \mathrm{v}$ slurry of Protein $\mathrm{G} /$ sepharose (GE Healthcare) was added ( $20 \mu \mathrm{l}$ beads per $\mathrm{ml}$ final concentration) and the suspension was shaken on ice for $1.5 \mathrm{~h}$. Working in a cold room, the immunoprecipitate was collected into a $50-\mathrm{mm}$ diameter fritted glass column (Bio-Rad) with vacuum suction and then washed with $200 \mathrm{ml}$ ice-cold IP buffer. The immunoprecipitate was suspended in $20 \mathrm{ml}$ telomerase buffer $(50 \mathrm{mM}$ HEPES$\mathrm{KOH}$ (pH 8.0), $300 \mathrm{mM} \mathrm{KCl}, 2 \mathrm{mM} \mathrm{MgCl}, 0.1 \% \mathrm{v} / \mathrm{v}$ Triton X-100, $10 \% \mathrm{v} / \mathrm{v}$ glycerol and $1 \mathrm{mM}$ DTT) containing $3 \mathrm{mg}$ peptide ARPAEEATSLEGALSGTRH (20 molar equiv per antibody, available from Abbexa Ltd). The suspension was incubated at RT for $1 \mathrm{~h}$ with gentle shaking every $5 \mathrm{~min}$, then the eluate was either collected (for use in assays requiring immunopurified telomerase) or transferred directly to a $25-\mathrm{mm}$ diameter fritted glass column (Bio-Rad) containing $15 \mathrm{nmol}$ gel-purified $5^{\prime}$-BIOTIN-CTAGACCTGTCATCA(TTAGGG) ${ }_{3}-3^{\prime}$ oligonucleotide immobilized on $500 \mu \mathrm{l}$ UltraLink Neutravidin Plus beads (Thermo-Fisher) (for the highly purified preparations in Figs $3 \mathrm{~d}$ and $4 \mathrm{~b}$ ). The suspension was rotated at RT for $30 \mathrm{~min}$ and then at $4{ }^{\circ} \mathrm{C}$ for $1 \mathrm{~h}$. For the work in this paper, it was necessary to elute telomerase in the presence of two different solution-phase DNA 'traps', so that this DNA (traces of which remain in the purified telomerase preparation) was identical to the substrates being tested: $6 \mathrm{ml}$ of suspension was collected in each of two $0.5-\mathrm{ml}$ micro-spin columns (GE Healthcare), and washed with $3 \mathrm{ml}$ cold telomerase buffer. After washing, columns were centrifuged for $10 \mathrm{~s}$ at $2,400 \times g$ to remove residual buffer. Each bead sample was suspended in $500 \mu \mathrm{l}$ telomerase buffer, followed by addition of $25 \mathrm{nmol}$ of one of two different solution-phase DNAs dissolved in $100 \mu$ l telomerase buffer: (i) 7GGT (Table 1) or (ii) [7GGT $]_{4}$ G-quadruplex. Activity-dependent elution was initiated by addition of $6 \mu \mathrm{l}$ dTTP + dATP (10 mM each deoxyribonucleotide triphosphate, final concentration $0.1 \mathrm{mM}$ ). The suspensions were rotated at RT for $30 \mathrm{~min}$ and the product solutions collected with centrifugation at 2,400g for $10 \mathrm{~s}$. Each product solution was layered on an 11 -ml $10 \rightarrow 40 \%$ glycerol gradient composed of $(20 \mathrm{mM}$ HEPES-KOH (pH 8.0), $300 \mathrm{mM} \mathrm{KCl}, 2 \mathrm{mM} \mathrm{MgCl}, 0.1 \%$ w/v octyl $\beta$-D-glucopyranoside and $1 \mathrm{mM}$ DTT) in Beckman Ultra-clear centrifuge tubes $(14 \times 89 \mathrm{~mm})$ for the Beckman SW-41 rotor. Telomerase was sedimented with centrifugation at 35,000 r.p.m. ( $\sim 210,000 \mathrm{~g}$ at $\left.r_{\max }\right)$ at $4^{\circ} \mathrm{C}$ for $20 \mathrm{~h}$. The tube was punctured at the bottom with a 30 -gauge needle, and $0.5-\mathrm{ml}$ fractions were collected by gravity. Fractions were assayed for telomerase concentration by dot-blot northern against hTR as described ${ }^{40}$, and equal amounts of enzyme used in each assay. Telomerase typically eluted in fractions $7-9 ; \sim 3-5$ pmol telomerase was obtained from each gradient. For extension assays using linear $7 \mathrm{GGT}$ or $[7 \mathrm{GGT}]_{4}$ as substrates (Fig. 3d), the enzyme prepared in the presence of the equivalent 'trap' DNA was used (with the [7GGT] $]_{4}$-trapped enzyme being used for the 'No DNA' lanes). Enzyme trapped with linear 7GGT was dialysed into telomerase buffer containing $2.5 \mathrm{mM} \mathrm{SrCl}_{2}$, and equal amounts of this enzyme used for the extension of 22GGG and $[22 \mathrm{GGG}]_{2}$ in Fig. $4 \mathrm{~b}$.

SDS-PAGE and silver-staining analysis of purified telomerase. A 50- $\mu$ l aliquot of purified telomerase, eluted in the presence of $[7 \mathrm{GGT}]_{4} \mathrm{G}$-quadruplex DNA, was placed in a Pierce Slide-a-Lyzer mini-dialysis cup (MWCO 3,500) and dialysed at RT for 30 min against $200 \mathrm{ml}$ of ( $20 \mathrm{mM}$ HEPES-KOH (pH 8.0), $20 \mathrm{mM} \mathrm{KCl,} 2 \mathrm{mM}$ $\mathrm{MgCl}_{2}, 20 \% \mathrm{v} / \mathrm{v}$ glycerol, $0.1 \% \mathrm{w} / \mathrm{v}$ octyl $\beta$-D-glucopyranoside and $1 \mathrm{mM} \mathrm{DTT}$ ). For SDS-PAGE, $30 \mu \mathrm{l}$ of the dialysed solution was combined with $10 \mu \mathrm{l} 10 \% \mathrm{w} / \mathrm{v}$ SDS, $5 \mu \mathrm{l} 1 \mathrm{M}$ DTT and $5 \mu \mathrm{l} 4 \times$ NuPAGE LDS loading buffer (Life Technologies). The sample was denatured at $80^{\circ} \mathrm{C}$ for $10 \mathrm{~min}$, cooled to RT and centrifuged at $16,000 \mathrm{~g}$ for $1 \mathrm{~min}$. A $20-\mu \mathrm{l}$ aliquot was electrophoresed over a NuPAGE $4-12 \%$ bis-Tris gradient mini-gel at $100 \mathrm{~V}$ for $3 \mathrm{~h}$. For the molecular weight marker, the Life Technologies Benchmark protein ladder was diluted 100-fold in $1 \times$ NuPAGE LDS loading buffer; from this, $3 \mu \mathrm{l}$ was diluted with $20 \mu \mathrm{l} 1 \times$ LDS buffer and loaded on the gel. Silver staining was performed with the Life Technologies SilverXpress kit.

DHX36 western blotting. A $25-\mu \mathrm{l}$ aliquot of immunopurified telomerase or four-step purified telomerase, eluted in the presence of $[7 \mathrm{GGT}]_{4}$ G-quadruplex
DNA, was combined with: $20 \mu \mathrm{l} \mathrm{H}_{2} \mathrm{O}, 25 \mu \mathrm{l} 4 \times$ NuPAGE LDS loading buffer, $10 \mu \mathrm{l}$ $1 \mathrm{M} \mathrm{DTT}$ and $20 \mu \mathrm{l} 10 \% \mathrm{w} / \mathrm{v}$ SDS. The samples were denatured at $80^{\circ} \mathrm{C}$ for $10 \mathrm{~min}$, cooled to RT and centrifuged at $16,000 \mathrm{~g}$ for $1 \mathrm{~min}$. A $30-\mu \mathrm{l}$ aliquot of each was electrophoresed over a NuPAGE $4-12 \%$ bis-Tris gradient mini-gel at $100 \mathrm{~V}$ for $4 \mathrm{~h}$. For the molecular weight marker, $2 \mu \mathrm{l}$ of the Life Technologies MagicMark-XP was used. Proteins were transferred to polyvinylidene difluoride membranes at $30 \mathrm{~V}$ for $90 \mathrm{~min}$. Blocking, washing, secondary anti-rabbit and chemiluminescent detection were performed using the Western Breeze reagents from Life Technologies. The primary anti-DHX36 antibody was polyclonal from rabbit, Abcam \#70269, diluted 1:500 in primary antibody diluent; probing was performed at RT for $2 \mathrm{~h}$. Figure $3 \mathrm{c}$ represents a 10-min exposure.

Dyskerin western blotting. HEK293T cell pellets were resuspended in $4 \times$ NuPAGE LDS loading buffer, $2 \% \beta$-mercaptoethanol and $2 \%$ Benzonase nuclease (Merck Millipore) at 10,000 cells per $\mu$. The samples were denatured at $68^{\circ} \mathrm{C}$ for $10 \mathrm{~min}$ and centrifuged at $16,000 \mathrm{~g}$ for $1 \mathrm{~min}$. A 5 - $\mu \mathrm{l}$ aliquot of each was electrophoresed over a NuPAGE $4-12 \%$ bis-Tris gradient mini-gel at $100 \mathrm{~V}$ for $2 \mathrm{~h}$. For the molecular weight marker, $5 \mu$ l of the Bio-Rad Preision Plus prestained marker was used. Proteins were transferred to nitrocellulose membrane at $100 \mathrm{~V}$ for 60 min. Membranes were blocked using 5\% skim milk, probed with primary antibodies diluted in $1 \%$ skim milk (mouse monoclonal anti-vinculin 1:5,000 (Sigma \#V9131) or polyclonal rabbit anti-dyskerin (in-house) 1:1,000) for $1 \mathrm{~h}$ at RT and washed $5 \times 5 \mathrm{~min}$ in TBST $(0.24 \%$ Tris-Cl, $0.05 \%$ Tris, $0.8 \% \mathrm{NaCl}$ and $0.1 \%$ Tween-20, $\mathrm{pH}$ 7.6). Membranes were then probed with horseradish peroxidaseconjugated secondary antibodies (goat anti-mouse or goat anti-rabbit; DAKO) diluted 1:5,000 in 1\% milk. Detection was performed with Amersham ECL Prime western blotting detection reagent and a FujiFilm Las4000 luminescent image analyzer, with autoexposure.

Telomerase activity assays. The following reaction was prepared to give $15 \mu \mathrm{l}$ per sample: between $1 \mathrm{nM}$ and $2 \mu \mathrm{M}$ of the specified oligonucleotide, $50 \mathrm{mM}$ Tris-HCl $\mathrm{pH} 8.5,1 \mathrm{mM} \mathrm{MgCl} 2,5 \mathrm{mM}$ DTT, $1 \mathrm{mM}$ spermidine- $\mathrm{HCl}, 0.5 \mathrm{mM}$ dTTP, $0.5 \mathrm{mM}$ dATP, $4.6 \mu \mathrm{M}$ non-radioactive dGTP and $0.33 \mu \mathrm{M}\left[\alpha^{-32} \mathrm{P}\right] \mathrm{dGTP}$ at $20 \mathrm{mCi} \mathrm{ml}^{-1}$, $6,000 \mathrm{Ci} \mathrm{mmol}^{-1}$ (PerkinElmer Life Sciences), $10 \%$ glycerol and either $150 \mathrm{mM}$ $\mathrm{KCl}$ for experiments with $7 \mathrm{GGT}$ or $2.5 \mathrm{mM} \mathrm{SrCl} 2$ for experiments with 22GGG. The reaction was initiated by adding $5 \mu$ of purified human telomerase, and incubating at $30^{\circ} \mathrm{C}$ for $1 \mathrm{~h}$. The reaction was quenched by the addition of $80 \mu \mathrm{l}$ of stop-buffer (50 mM Tris- $\mathrm{HCl}, \mathrm{pH} 8.3,20 \mathrm{mM}$ EDTA and $0.2 \% \mathrm{SDS}$ ) and $1-2 \times 10^{3}$ c.p.m. of a $5^{\prime}-{ }^{32} \mathrm{P}$-labelled synthetic 100 -mer DNA as an internal recovery standard. The solution was extracted with an equal volume of phenol/ chloroform/isoamyl alcohol $(25: 24: 1, \mathrm{v} / \mathrm{v} / \mathrm{v})$ and precipitated with ethanol in the presence of $2.5 \mathrm{M} \mathrm{NH}_{4} \mathrm{OAc}$. The pellet was air-dried at RT for $15 \mathrm{~min}$ and dissolved in $5 \mu \mathrm{l}$ TE buffer (10 mM Tris-HCl, $\mathrm{pH} 8.0$ and $1 \mathrm{mM}$ EDTA, $\mathrm{pH} 8.0$ ), followed by addition of $5 \mu \mathrm{l}$ formamide buffer ( $90 \%$ deionized formamide, $0.1 \%$ bromopheno blue and $0.1 \%$ xylene cyanol in $1 \times \mathrm{TBE}$ ). The solution was heated at $90^{\circ} \mathrm{C}$ for $5 \mathrm{~min}$, and $3 \mu \mathrm{l}$ was electrophoresed over a $10 \%$ polyacrylamide sequencing gel $(0.2 \mathrm{~mm}$ thick $\times 40 \mathrm{~cm}$ length $\times 35 \mathrm{~cm}$ width, 32-well comb) run in $1 \times \mathrm{TBE} / 8 \mathrm{M}$ urea at $85 \mathrm{~W}$. The gel was transferred to filter paper, dried for $30 \mathrm{~min}$ at $80^{\circ} \mathrm{C}$, exposed to a PhosphorImager screen, visualized on a Typhoon FLA9500 scanner (GE Healthcare Lifesciences) and analysed using ImageQuant software. The total intensities of extension products were normalized against the intensity of the ${ }^{32} \mathrm{P}$-labelled 100-mer recovery and loading control. Resulting values were expressed as a percentage of the reaction with maximal activity and plotted against substrate concentrations and fitted to the Michaelis-Menten equation to give $K_{\mathrm{m}}$ values.

For experiments where dTTP was titrated, the oligonucleotide concentration was kept at $1 \mu \mathrm{M}$ and the concentration of dTTP was changed as outlined in the figure legend. All other reagents and procedures remained the same. Activity assays testing templated addition included $1-2 \mu \mathrm{M}$ of the specified oligonucleotide and the following combinations and concentrations of labelled and unlabelled nucleotides; all other reaction conditions remained the same.

7GGT: T,A lanes: ${ }^{32} \mathrm{P}$-dTTP $\left(25 \mu \mathrm{M}, 80 \mathrm{Ci} \mathrm{mmol}^{-1}\right)$ and dATP $(0.5 \mathrm{mM})$

T,A,ddG lanes: ${ }^{32} \mathrm{P}$-dTTP $\left(25 \mu \mathrm{M}, 80 \mathrm{Ci} \mathrm{mmol}^{-1}\right)$, dATP $(0.5 \mathrm{mM})$ and ddGTP $(0.5 \mathrm{mM})$.

T,A,G lanes: ${ }^{32} \mathrm{P}$-dTTP $\left(25 \mu \mathrm{M}, 80 \mathrm{Ci} \mathrm{mmol}^{-1}\right)$, dATP $(0.5 \mathrm{mM})$ and dGTP $(0.5 \mathrm{mM})$ or dTTP $(0.5 \mathrm{mM})$, dATP $(0.5 \mathrm{mM})$ and ${ }^{32} \mathrm{P}$-dGTP $(5 \mu \mathrm{M}$, $400 \mathrm{Ci} \mathrm{mmol}^{-1}$ ).

22GGG:T,A lanes: ${ }^{32} \mathrm{P}$-dTTP $\left(3 \mu \mathrm{M}, 150 \mathrm{Ci} \mathrm{mmol}^{-1}\right)$ and ddATP $(25 \mu \mathrm{M})$.

T,A,ddG lanes: ${ }^{32} \mathrm{P}$-dTTP $\left(3 \mu \mathrm{M}, 160 \mathrm{Ci} \mathrm{mmol}^{-1}\right)$, dATP $(0.5 \mathrm{mM})$ and ddGTP $(25 \mu \mathrm{M})$

T,A,G lanes: dTTP $(0.5 \mathrm{mM})$, dATP $(0.5 \mathrm{mM})$ and ${ }^{32} \mathrm{P}-\mathrm{dGTP}(5 \mu \mathrm{M}$, $400 \mathrm{Ci} \mathrm{mmol}^{-1}$ ).

Experiments in which reaction products were subjected to native gel electrophoresis contained $2 \mu \mathrm{M}$ DNA, $0.7 \mu \mathrm{M}$ non-radioactive dTTP and $0.33 \mu \mathrm{M}$ $\left[\alpha-{ }^{32} \mathrm{P}\right] \mathrm{dTTP}$ at $10 \mathrm{mCi} \mathrm{ml}^{-1}, 3,000 \mathrm{Ci} \mathrm{mmol}^{-1}$, with all other reaction conditions remaining the same. The reaction was quenched by the addition of $20 \mu \mathrm{l}$ of stop-buffer (see above) and $8 \times 10^{3}$ c.p.m. of a $5^{\prime}-{ }^{32} \mathrm{P}$-labelled synthetic 100 -mer DNA as an internal recovery standard. The product was purified of unincorporated deoxyribonucleotide triphosphates using two rounds of mini Quick Spin Oligo column purification (Roche). Prior to use, Quick Spin Oligo columns were equilibrated by centrifugation twice at $1,000 \mathrm{~g}$ for $10 \mathrm{~min}$ with $400 \mu \mathrm{l} \mathrm{Sr^{2 } +} \mathrm{hTel}$ 
buffer (see above). The purified product was added to $6 \times$ native gel loading buffer (see above) and electrophoresed on a non-denaturing $16 \%$ polyacrylamide gel containing $2.5 \mathrm{mM} \mathrm{SrCl}_{2}$ for $\sim 48 \mathrm{~h}$ at $40 \mathrm{~V}$ at $18^{\circ} \mathrm{C}$. Both buffer and gel contained the same constituents as the DNA-folding buffer. The gel was transferred to filter paper, dried for $30 \mathrm{~min}$ at $80^{\circ} \mathrm{C}$, exposed to a PhosphorImager screen, visualized on a Typhoon FLA9500 scanner and analysed using ImageQuant software.

Expression and purification of G-quadruplex antibody (BG4). BG4-encoding plasmid (from the laboratory of Professor Shankar Balasubramanian, University of Cambridge, UK) was transformed into BL21(DE3) competent cells (Stratagene), which were cultured in TY media (1.6\% tryptone peptone, $1 \%$ yeast extract and $0.5 \% \mathrm{NaCl}$ ) and $50 \mu \mathrm{g} \mathrm{ml}^{-1}$ kanamycin. BG4 antibody expression was induced with $0.5 \mathrm{mM}$ isopropyl $\beta$-D-1-thiogalactopyranoside for $3 \mathrm{~h}$ at $37^{\circ} \mathrm{C}$. The cells were lysed in TES buffer (50 mM Tris-Cl pH 8.0, $1 \mathrm{mM}$ EDTA and 20\% sucrose) on ice for $10 \mathrm{~min}$, diluted twofold in water, and left on ice for a further $10 \mathrm{~min}$ prior to centrifugation at $10,000 \mathrm{~g}$ at $4{ }^{\circ} \mathrm{C}$ for $30 \mathrm{~min}$. The supernatant was filtered $(0.2 \mu \mathrm{m})$ and purified on a HIS-Select Nickel Affinity column (Sigma). The column was washed in $10 \mathrm{mM}$ imidazole pH 8.0 in PBS, and BG4 antibody eluted in $250 \mathrm{mM}$ imidazole pH 8.0 in PBS. BG4 antibody was concentrated and buffer exchanged into PBS in an Amicon Ultra-15 Centrifugal Filter Unit (Millipore). The concentration of BG4 was determined using Thermo Scientific Pierce BCA Protein Assay kit, and the antibody was stored at $-20^{\circ} \mathrm{C}$.

\section{Cell synchronization and short interfering RNA (siRNA) transfection.}

HEK293T mid-S-phase cell synchronization was performed using cells released from a thymidine/aphidicolin block as previously described ${ }^{49}$. Dyskerin knockdown was performed by reverse transfecting $120 \mathrm{pmol}$ of Invitrogen custom-designed Stealth siRNA targeting either the dyskerin $3^{\prime}$ untranslated region (siDKC\#1, 5'-AAGGCCACUUGAAGCUGGAGGAGAA- $3^{\prime}$ ) or the coding region (siDKC\#2, 5'-GGCCAAGATTATGCTTCCAGGTGTT- $3^{\prime}$ ). Cells were transfected using Life Technologies Lipofectamine RNAiMAX Transfection Reagent. Qiagen All Stars negative-control siRNA was used as a siRNA control.

Immunofluorescence and telomere/telomerase FISH. Immunofluorescence and FISH for telomeres and telomerase RNA (hTR) were performed as described ${ }^{49}$, with the following modifications. Cytoplasm was removed by incubating slides in cytoplasmic extraction buffer (20 mM HEPES-KOH, pH 7.9, $20 \mathrm{mM} \mathrm{NaCl}, 5 \mathrm{mM}$ $\mathrm{MgCl}_{2}, 300 \mathrm{mM}$ sucrose and $\left.0.5 \%(\mathrm{v} / \mathrm{v}) \mathrm{NP}-40\right)$ for $10 \mathrm{~min}$ with no shaking. Slides were washed once with PBS $+0.1 \%$ Tween-20, once with PBS and then fixed in $2 \%$ paraformaldehyde in PBS for $20 \mathrm{~min}$. Cells were washed with PBS then incubated in $0.1 \%$ Triton X-100 in PBS for 10 min, followed by rinsing twice in PBS. Slides were ethanol dehydrated with $70 \%$ ( $2 \mathrm{~min}$ ), $90 \%$ ( $2 \mathrm{~min}$ ) and 100\% ethanol (2 min) followed by air drying prior to overlaying with $30 \mu \mathrm{l}$ of FISH buffer containing $5 \mathrm{ng}$ each of five Alexa Fluor 488-labelled anti-hTR oligonucleotides and $5 \mathrm{ng}$ of Texas Red-labelled telomere probe ${ }^{49}$. Slides were heated to $80^{\circ} \mathrm{C}$ for $3 \mathrm{~min}$ and incubated in a humidified chamber overnight at $37^{\circ} \mathrm{C}$ and washed ${ }^{49}$. Slides were refixed in $2 \%$ paraformaldehyde in PBS, washed as before and overlaid with phosphatebuffered gelatin ${ }^{49}$ for $1 \mathrm{~h}$. Slides were incubated with BG4 primary antibody $(600 \mathrm{nM})$ for $1 \mathrm{~h}$ at $37^{\circ} \mathrm{C}$, washed four times for $5 \mathrm{~min}$ with PBS $+0.01 \%$ Tween-20 and then overlaid with secondary antibody (Rabbit anti-DYKDDDDK Tag Antibody, Cell Signalling; 1:800 dilution) for $1 \mathrm{~h}$ at $37^{\circ} \mathrm{C}$. Cells were washed as before and a fluorescently labelled tertiary antibody (Alexa Fluor 647 Donkey Anti-Rabbit IgG (H + L) Antibody, Life Technologies; 1:1,000 dilution) was overlaid at $37^{\circ} \mathrm{C}$ for $30 \mathrm{~min}$, washed as before and counterstained with 4',6-diamidino-2-phenylindole. Staining was visualized at RT on a Zeiss Axio Imager M1 microscope, with a Plan-Apochromat $\times 63$ oil objective (numerical aperture, 1.4), and an AxioCam MR digital camera (Carl Zeiss) with consistent exposure times between experiments. For presentation purposes, pixel intensity histograms were adjusted in Axiovision (Carl Zeiss), equally across all figure panels, and images were cropped in Adobe Photoshop.

\section{References}

1. de Lange, T. et al. Structure and variability of human chromosome ends. Mol. Cell. Biol. 10, 518-527 (1990).

2. Moyzis, R. K. et al. A highly conserved repetitive DNA sequence, (TTAGGG) present at the telomeres of human chromosomes. Proc. Natl Acad. Sci. USA 85, 6622-6626 (1988).

3. Harley, C. B., Futcher, A. B. \& Greider, C. W. Telomeres shorten during ageing of human fibroblasts. Nature 345, 458-460 (1990).

4. Allsopp, R. C. et al. Telomere length predicts replicative capacity of human fibroblasts. Proc. Natl Acad. Sci. USA 89, 10114-10118 (1992).

5. Greider, C. W. \& Blackburn, E. H. Identification of a specific telomere terminal transferase activity in Tetrahymena extracts. Cell 43, 405-413 (1985).

6. Greider, C. W. \& Blackburn, E. H. The telomere terminal transferase of Tetrahymena is a ribonucleoprotein enzyme with two kinds of primer specificity. Cell 51, 887-898 (1987).

7. Lingner, J. et al. Reverse transcriptase motifs in the catalytic subunit of telomerase. Science 276, 561-567 (1997).
8. Feldser, D. M. \& Greider, C. W. Short telomeres limit tumor progression in vivo by inducing senescence. Cancer Cell 11, 461-469 (2007).

9. Shay, J. W. \& Bacchetti, S. A survey of telomerase activity in human cancer. Eur. J. Cancer 33, 787-791 (1997).

10. Williamson, J. R., Raghuraman, M. K. \& Cech, T. R. Monovalent cationinduced structure of telomeric DNA: the G-quartet model. Cell 59, 871-880 (1989).

11. Burge, S., Parkinson, G. N., Hazel, P., Todd, A. K. \& Neidle, S. Quadruplex DNA: sequence, topology and structure. Nucleic Acids Res. 34, 5402-5415 (2006).

12. Huppert, J. L. \& Balasubramanian, S. Prevalence of quadruplexes in the human genome. Nucleic Acids Res. 33, 2908-2916 (2005).

13. Siddiqui-Jain, A., Grand, C. L., Bearss, D. J. \& Hurley, L. H. Direct evidence for a G-quadruplex in a promoter region and its targeting with a small molecule to repress c-MYC transcription. Proc. Natl Acad. Sci. USA 99, 11593-11598 (2002).

14. Kumari, S., Bugaut, A., Huppert, J. L. \& Balasubramanian, S. An RNA G-quadruplex in the 5' UTR of the NRAS proto-oncogene modulates translation. Nat. Chem. Biol. 3, 218-221 (2007).

15. Gomez, D. et al. Telomerase downregulation induced by the G-quadruplex ligand 12459 in A549 cells is mediated by hTERT RNA alternative splicing. Nucleic Acids Res. 32, 371-379 (2004).

16. Smith, J. S. et al. Rudimentary G-quadruplex-based telomere capping in Saccharomyces cerevisiae. Nat. Struct. Mol. Biol. 18, 478-485 (2011).

17. Schaffitzel, C. et al. In vitro generated antibodies specific for telomeric guanine-quadruplex DNA react with Stylonychia lemnae macronuclei. Proc. Natl Acad. Sci. USA 98, 8572-8577 (2001).

18. Biffi, G., Tannahill, D., McCafferty, J. \& Balasubramanian, S. Quantitative visualization of DNA G-quadruplex structures in human cells. Nat. Chem. 5, 182-186 (2013).

19. Shi, D. F., Wheelhouse, R. T., Sun, D. \& Hurley, L. H. Quadruplex-interactive agents as telomerase inhibitors: synthesis of porphyrins and structure-activity relationship for the inhibition of telomerase. J. Med. Chem. 44, 4509-4523 (2001).

20. Cuesta, J., Read, M. A. \& Neidle, S. The design of G-quadruplex ligands as telomerase inhibitors. Mini Rev. Med. Chem. 3, 11-21 (2003).

21. De Cian, A. et al. Targeting telomeres and telomerase. Biochimie 90, 131-155 (2008).

22. Zahler, A. M., Williamson, J. R., Cech, T. R. \& Prescott, D. M. Inhibition of telomerase by G-quartet DNA structures. Nature 350, 718-720 (1991).

23. Oganesian, L., Moon, I. K., Bryan, T. M. \& Jarstfer, M. B. Extension of G-quadruplex DNA by ciliate telomerase. EMBO J. 25, 1148-1159 (2006).

24. Brown, A. F. et al. A self-regulating template in human telomerase. Proc. Natl Acad. Sci. USA 111, 11311-11316 (2014).

25. Blackburn, E. H. \& Collins, K. Telomerase: an RNP enzyme synthesizes DNA Cold Spring Harb. Perspect. Biol. 3, a003558 (2011).

26. Wang, H. \& Blackburn, E. H. De nova telomere addition by Tetrahymena telomerase in vitro. EMBO J. 16, 866-879 (1997).

27. Sauerwald, A. et al. Structure of active dimeric human telomerase. Nat. Struct. Mol. Biol. 20, 454-460 (2013).

28. Jiang, J. et al. The architecture of Tetrahymena telomerase holoenzyme. Nature 496, 187-192 (2013).

29. Mergny, J. L., De Cian, A., Ghelab, A., Sacca, B. \& Lacroix, L. Kinetics of tetramolecular quadruplexes. Nucleic Acids Res. 33, 81-94 (2005).

30. Pedroso, I. M., Duarte, L. F., Yanez, G., Baker, A. M. \& Fletcher, T. M. Induction of parallel human telomeric G-quadruplex structures by $\operatorname{Sr}(2+)$. Biochem. Biophys. Res. Commun. 358, 298-303 (2007).

31. Chen, F. M. Sr2 + facilitates intermolecular G-quadruplex formation of telomeric sequences. Biochemistry 31, 3769-3776 (1992).

32. Wang, Y. \& Patel, D. J. Guanine residues in $d\left(T_{2} A_{G}\right)$ and $d\left(T_{2} G_{4}\right)$ form parallel-stranded potassium cation stabilized G-quadruplexes with anti glycosidic torsion angles in solution. Biochemistry 31, 8112-8119 (1992).

33. Williamson, J. R. G-quartet structures in telomeric DNA. Annu. Rev. Biophys Biomol. Struct. 23, 703-730 (1994).

34. Mergny, J. L., Li, J., Lacroix, L., Amrane, S. \& Chaires, J. B. Thermal difference spectra: a specific signature for nucleic acid structures. Nucleic Acids Res. 33, e138 (2005).

35. Gornall, K. C., Samosorn, S., Talib, J., Bremner, J. B. \& Beck, J. L. Selectivity of an indolyl berberine derivative for tetrameric G-quadruplex DNA. Rapid Commun. Mass Spectrom. 21, 1759-1766 (2007).

36. Rosu, F., Gabelica, V., Houssier, C., Colson, P. \& Pauw, E. D. Triplex and quadruplex DNA structures studied by electrospray mass spectrometry. Rapid Commun. Mass Spectrom. 16, 1729-1736 (2002).

37. Oganesian, L., Graham, M. E., Robinson, P. J. \& Bryan, T. M. Telomerase recognizes G-quadruplex and linear DNA as distinct substrates. Biochemistry 46, 11279-11290 (2007). 
38. Raghuraman, M. K. \& Cech, T. R. Effect of monovalent cation-induced telomeric DNA structure on the binding of Oxytricha telomeric protein. Nucleic Acids Res. 18, 4543-4552 (1990).

39. Zaug, A. J., Podell, E. R. \& Cech, T. R. Human POT1 disrupts telomeric G-quadruplexes allowing telomerase extension in vitro. Proc. Natl Acad. Sci. USA 102, 10864-10869 (2005).

40. Jurczyluk, J. et al. Direct involvement of the TEN domain at the active site of human telomerase. Nucleic Acids Res. 39, 1774-1788 (2011).

41. Cohen, S. B. \& Reddel, R. R. A sensitive direct human telomerase activity assay. Nat. Methods 5, 355-360 (2008).

42. Cohen, S. B. et al. Protein composition of catalytically active human telomerase from immortal cells. Science 315, 1850-1853 (2007).

43. Lattmann, S., Stadler, M. B., Vaughn, J. P., Akman, S. A. \& Nagamine, Y. The DEAH-box RNA helicase RHAU binds an intramolecular RNA G-quadruplex in TERC and associates with telomerase holoenzyme. Nucleic Acids Res. 39, 9390-9404 (2011)

44. Sexton, A. N. \& Collins, K. The 5 ' guanosine tracts of human telomerase RNA are recognized by the G-quadruplex binding domain of the RNA helicase DHX36 and function to increase RNA accumulation. Mol. Cell. Biol. 31, 736-743 (2011).

45. Nicoludis, J. M., Barrett, S. P., Mergny, J. L. \& Yatsunyk, L. A. Interaction of human telomeric DNA with $N$-methyl mesoporphyrin IX. Nucleic Acids Res. 40, 5432-5447 (2012).

46. Nicoludis, J. M. et al. Optimized end-stacking provides specificity of $N$-methyl mesoporphyrin IX for human telomeric G-quadruplex DNA. J. Am. Chem. Soc. 134, 20446-20456 (2012).

47. Tippana, R., Xiao, W. \& Myong, S. G-quadruplex conformation and dynamics are determined by loop length and sequence. Nucleic Acids Res. 42, 8106-8114 (2014).

48. Tomlinson, R. L. et al. Telomerase reverse transcriptase is required for the localization of telomerase RNA to Cajal bodies and telomerese in human cancer cells. Mol. Biol. Cell 19, 3793-3800 (2008).

49. Stern, J. L., Zyner, K. G., Pickett, H. A., Cohen, S. B. \& Bryan, T. M. Telomerase recruitment requires both TCAB1 and Cajal bodies independently. Mol. Cell. Biol. 32, 2384-2395 (2012).

50. Ray, S. et al. RPA-mediated unfolding of systematically varying G-quadruplex structures. Biophys. J. 104, 2235-2245 (2013).

51. Zhang, M. L. et al. Yeast telomerase subunit Estlp has guanine quadruplexpromoting activity that is required for telomere elongation. Nat. Struct. Mol. Biol. 17, 202-209 (2010).

52. Sen, D. \& Gilbert, W. Formation of parallel four-stranded complexes by guanine-rich motifs in DNA and its implications for meiosis. Nature 334, 364-366 (1988).

53. Canudas, S. et al. A role for heterochromatin protein $1 \gamma$ at human telomeres. Genes Dev. 25, 1807-1819 (2011).

54. Colgin, L. M. et al. The hTERT $\alpha$ splice variant is a dominant negative inhibitor of telomerase activity. Neoplasia 2, 426-432 (2000).

55. Evans, M. J., Hartman, S. L., Wolff, D. W., Rollins, S. A. \& Squinto, S. P. Rapid expression of an anti-human C5 chimeric Fab utilizing a vector that replicates in COS and 293 cells. J. Immunol. Methods 184, 123-138 (1995).
56. Fu, D. \& Collins, K. Distinct biogenesis pathways for human telomerase RNA and H/ACA small nucleolar RNAs. Mol. Cell 11, 1361-1372 (2003).

57. Palmiter, R. D. Magnesium precipitation of ribonucleoprotein complexes. Expedient techniques for the isolation of undergraded polysomes and messenger ribonucleic acid. Biochemistry 13, 3606-3615 (1974).

\section{Acknowledgements}

We are grateful to Timothy Adams (CSIRO, Parkville, VIC, Australia) for providing pAPEX vectors, and for consultation on overexpression of telomerase. We thank Jessie Zhang for help with siRNA transfections, and Grant Griffiths and Nathan Zammit for contributing data at an early stage of the project. We thank Shankar Balasubramanian (University of Cambridge, Cambridge, United Kingdom) for providing the plasmid encoding the BG4 antibody. We thank the Australian Research Council for the mass spectrometers used in this work. This research was supported by project grants awarded by the Cancer Council NSW (RG11/07, RG12/01 and RG12/02) and the National Health and Medical Research Council (571073). K.G.Z. was supported by an Australian Postgraduate Award and a Cancer Institute NSW PhD Scholarship, A.L.M. by a Denise Higgins Scholarship, and T.M.B. by a Career Development Fellowship from the Cancer Institute NSW (11/CDF/3-05).

\section{Author contributions}

K.C.P., A.L.M. and T.M.B. conceived the project and designed experiments. A.L.M., K.C.P., S.B.C., K.G.Z., N.S. and T.M.B. carried out experiments. T.P. and G.O.L. performed large-scale culture of telomerase-overexpressing cells. K.C.P. and J.L.B. performed and interpreted mass spectrometry analysis. All authors contributed to writing the manuscript.

\section{Additional information}

Supplementary Information accompanies this paper at http://www.nature.com/ naturecommunications.

Competing financial interests: The hTERT antibody, CMRI 276-294, antigenic release peptide and telomerase overexpressing HEK293T cells are available to researchers from Abbexa Ltd, under exclusive license from the authors institution, Children's Medical Research Institute.

Reprints and permission information is available online at http://npg.nature.com/ reprintsandpermissions/

How to cite this article: Moye, A. L. et al. Telomeric G-quadruplexes are a substrate and site of localization for human telomerase. Nat. Commun. 6:7643 doi: 10.1038/ncomms8643 (2015).

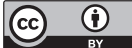

This work is licensed under a Creative Commons Attribution 4.0 International License. The images or other third party material in this article are included in the article's Creative Commons license, unless indicated otherwise in the credit line; if the material is not included under the Creative Commons license, users will need to obtain permission from the license holder to reproduce the material. To view a copy of this license, visit http://creativecommons.org/licenses/by/4.0/ 